Geophysica (1998), 34(3), 179-207

\title{
The Dissipation Subrange in Wind Wave Spectra
}

\author{
S.A. Kitaigorodskii \\ Finnish Meteorological Institute, P. O. Box 503, FIN-00101 Helsinki, Finland \\ (On leave from the Russian Academy of Sciences, Institute of Oceanology, Moscow)
}

(Received: March 1998; Accepted: September 1998)

\begin{abstract}
In this paper an attempt is made to summarize the results of recent field experiments (Leikin and Rozenberg, 1984, Tang and Shemdin, 1983, Birch and Ewing, 1986, Hansen et al., 1990, Banner et al., 1989, Banner, 1990, and some others) with the purpose to demonstrate that the rapid spectral cut off, needed for determination of the boundaries of the dissipation subrange in the wave number frequency range, seems to be an intrinsic property of well-developed seas.

It is shown that in the dissipation subrange the spectrum most likely has the form $S(\omega)=\beta g^{2} \omega^{-5}$, where $\beta=0,025, g$ is acceleration due to gravity, and energy dissipation restricted to a range of frequencies $\omega>\omega_{g}$, much higher than frequencies of dominant waves, or frequencies where weak nonlinear interactions can produce direct energy cascade (Kitaigorodskii, 1983, Zakharoff, 1992). The characteristics of the transition from rear high-frequency and high-wave number parts of wave spectra to the dissipation subrange are summarized.

In this paper, which has much in common with the authors previous publications (S.A. Kitaigorodskii 1992 a, b), there are a few new, but important elements. First of all, in data analyses a distinction has been made between space and time average statistical characteristics of the wind-wave field. Than, in analysis of spatial characteristics new experimental data have been added. Among them, the Lupyan and Sharkov (1989) data on two-dimensional spatial wind-wave spectra in the Caspian Sea at large fetches, and results of Jahne and Riemer's (1990) laboratory studies of spatial wind-wave spectra measured by optical methods. According to the Lupyan and Sharkov (1989) spectra, the transitional (to the dissipation subrange) wave number $k_{g}$ has been found to be equal to 1,8-2,0 $\mathrm{m}^{-1}$ (against the SWOP (Stereo Wave Observation Project) value $k_{g}=0,2 \mathrm{~m}^{-1}$ ), i.e., for wavelengths of the order of several meters. On the other hand, the nondimensional frequencies $\omega_{g} U_{a} / g$, corresponding to the spatial Lupyan - Sharkov spectra, have been found to lie in the range 2,65-2,80, which is very close to the value of $\omega_{g} U_{a} / g$ in $S W O P$, equal to 2,5-3,7. The Lupyan - Sharkov data are not in contradiction with a tendency of $\omega_{g} U_{a_{-}} / g$ to diminish with fetch. Such behaviour of $\omega_{g} U_{a} / g$ has been clearly established in this paper due to the Jahne and Riemer laboratory data (1990), where the transitional wave number $k_{g}$ and frequency $\omega_{g}$ have been determined for poorly studied and little known small fetches (for $g X / U_{a}^{2}=3,0-11,0$ the values of $\omega_{g} U_{a} / g$ were around 50, and it was for such wave numbers $k_{g}$ as $\left.160 \mathrm{~m}^{-1}\right)$. By using the Jahne and Riemer data, we have extended the previously found relationship between $\omega_{g} U_{a} / g$ and $\omega_{p} U_{a} / g$, $\omega_{p}$ - peak frequencies, to fairly large values of $\omega_{g} U_{a} / g$ (see Fig. 1). Moreover, in this work attention has been given to the description of the relation between the boundaries of the dissipation subrange, derived from standard spectral characteristics of wind waves, and the inner scale in the fractal description of the developed sea surface. This has been done using the recently published results of Zakharoff (1992), who has been made an attempt to determine conditions of the sea surface fractalization due to surface tension effects.
\end{abstract}

Key words: Wave forecasting, physics of nonlinear interaction, data analysis, wave spectra 


\section{Introduction}

Since the 1981 symposium on wave dynamics and radio probing of the ocean surface in Miami many interesting publications about the equilibrium spectra of wind waves appeared in oceanographic literature. Beginning with the work's of Kitaigorodskii (1983) and Phillips (1985), a great deal of attention was devoted to the explanation of the wind speed dependence of the rear face of the spectra of surface gravity waves. This has been done either by using concepts of statistical equilibrium of the Kolmogoroff's type in weakly nonlinear surface gravity wave field (Kitaigorodskii, 1983, Zakharoff and Zaslavskii, 1982), or by use of alternative model based on the balance of source terms (Phillips, 1985, Komen et al., 1984). The forms of the equilibrium spectra in these two models are not too different from each other (Kitaigorodskii, 1987), which make it difficult to distinguish between the types of statistical equilibrium only on the basis of the information about the rear faces of the frequency and wave number spectra. This becomes even more evident, after work by Banner (1990), who has devoted special attention to the probably underestimated before the important role of k-dependent type of angular distribution of wave energy propagation in shaping rear faces of frequency wave spectra not far from its peak. This viewpoint was just briefly mentioned in Kitaigorodskii et al. (1975) (see footnotes on p, 114 in this paper), whereas Banner (1990) has been trying to establish empirically the canonical form of wave spectra in the whole energy containing region of the twodimensional wave spectra $\psi_{\mathrm{s}}(\mathrm{k})=\psi_{\mathrm{s}}(\mathrm{k}, \theta),(\mathrm{k}=(\mathrm{k} \cos \theta, \mathrm{k} \sin \theta)$.

Contrary to asymptotic arguments of statistical equilibrium in weakly nonlinear field of surface gravity waves, which leads to wind dependence of $\psi_{\mathrm{s}}(\mathrm{k}, 0)$ through the dependence of energy and action fluxes from wind speed (Kitaigorodskii, 1983, 1987), Banner (1990) formulated 2-D wave number spectral model using empirical form of directional frequency spectra of Donelan et al., (1985), with extrapolation of their $\omega<3$ $\omega_{\mathrm{p}}$ form, to much higher wave numbers. Banner (1990) argues $\mathrm{k}^{-4}$ form of the rear side of the $\psi(\mathrm{k}, \vartheta)$ above the peak enhancement region is in agreement with latest observations, and that the broad directional distribution (independent of $\mathrm{k} / \mathrm{k}_{\mathrm{p}}$ values, $\mathrm{k}_{\mathrm{p}}$ peak wave number) occurs approximately only at $\mathrm{k} / \mathrm{k}_{\mathrm{p}}>10$, For smaller $\mathrm{k} / \mathrm{k}_{\mathrm{p}}$ Banner's (1990) model demonstrates that the prescribed spreading function according to Donelan et al., (1985), can easily explain two observed features in frequency spectra of ocean gravity waves, i.e. wind dependence in the region close to the peak $\left(\omega / \omega_{p} \leq 3\right)$, and transition from $\omega^{-4}$ to $\omega^{-5}$ form, at frequencies which noticeably varies with $\omega_{\mathrm{p}}$ (!). Banner (1990) shows that intrinsic frequency spectrum transitions from $\omega^{-4}$ to $\omega^{-5}$ form around 6-10 k . Contrary to Banner (1990) conclusions, Kitaigorodskii (1983) idea has received some support in the paper by Hansen et al. (1990), where transition to $\omega^{-5}$ form in the frequency spectra was found to be consistent with transition to $\mathrm{k}^{-4}$ form in high wave number region of spatial spectra $\psi(\mathrm{k})$. The transition from wind dependent $\mathrm{k}^{-7 / 2}$ form of spatial spectrum $\psi(\mathrm{k})$ to $\mathrm{k}^{-4}$ form, which according to Kitaigorodskii (1983) 
indicates the dissipation subrange, appears in the data of SWOP experiments (cf. recalculations of SWOP data in Kitaigorodskii (1984). To my knowledge this was long time the only direct evidence of occurrence of the more rapid (then $\mathrm{k}^{-7 / 2}$ ) spectral fall off in high wave number tail of wave number spectra. Of course, the data which contains $\psi$ $(\mathrm{k}, \vartheta)$ spectra, satisfying $\mathrm{k}^{-4}$ form, are much more numerous (Phillips, 1977). The latest among them seems to be Banner et al. (1989) recent stereophoto measurements of $\mathrm{k}^{-4}$ form in the range of short wavelengths 0,2-1,6 m, which we'll analyze later. The very question about the existence of the dissipation subrange is far from being only of academic interest: the radar backscattering wind dependence and wave number dependence can be explained only by knowing the behavior of high frequency and high wave number tails of the spectrum. Indeed the dissipation subrange according to radar returns must be observed (or exist) at wave numbers much higher than those which were originally found by Phillips in 1958 (Phillips, 1958) and Phillips (1977). For example the data analyzed recently by $W u$ (1990) in respect to the variations of the radar return with surface wave number, seems to locate the dissipation subrange in the range $12 \mathrm{~cm}$ $>\lambda>1,25 \mathrm{~cm}$. This appears to be a rather extreme conclusion: for example, the results of recent stereophotography indicating a $\mathrm{k}^{-4}$ form with broad angular distribution in the range of wave lengths 20-150 cm (Banner et al., 1989) can be considered also as an evidence of the existence of the dissipation subrange. $W u$ (1990) analysis seems to be rather in accord with Phillips (1985) assertion that the equilibrium range prevails for gravity wave components, where dissipation subrange exist only for shortest gravity and gravity-capillary wave components. Note also that in situ measurements used by Kitaigorodskii (1983) and Phillips (1985) were limited to components no shorter than say 1-1,5 m. Thus according to these authors, as well as Banner et al. (1989), it seems that the typical value of upper bound of dissipation subrange is 1-1,5 meter (!). However it must not be forgotten also that according to Kitaigorodskii (1983) and Hansen et al. (1990) analyses the typical transitional wave number $\mathrm{k}_{\mathrm{g}}$ and frequency $\omega_{\mathrm{g}}$ for the "beginning" of dissipation subrange in wave spectra depend both on wind speed and the stage of development (decrease of $\mathrm{k}_{\mathrm{g}}$ and $\omega_{\mathrm{g}}$ with wind speed, as well as with fetch or duration (cf Fig. 5 in Hansen et al. (1990)). Thus we can expect that for young waves and not high wind speeds the dissipation "subrange" is moving to the "microscales" of shortest gravity ripples and capillary gravity waves, where for moderate and strong winds and rather well developed waves, dissipation "subrange" can be observed in more wide ranges of wave numbers and frequencies higher than the peak values, but lower than the scales of gravity capillary ripples. Still the available information about transitional frequency $\omega_{\mathrm{g}}$ according to Kitaigorodskii (1983), Hansen et al. (1990), doesn't show a big variation in $\omega_{\mathrm{g}}$, whose typical value looks close to $4 \mathrm{~g} / \mathrm{U}_{\mathrm{a}}\left(\mathrm{U}_{\mathrm{a}}\right.$ - wind speed). The very fact that the dissipation subrange (in wave number space) is characterized by power exponent 4 , give rise to the attempts to characterize the surface geometry in equilibrium range (with smaller power exponents, where both direct energy cascade and wind input can occur) by the use of fractal dimensions which in such case 
becomes both relevant and useful (Glazman, 1988). It is interesting that the rapid spectral fall off needed for determination of the boundary of dissipation subrange seems to be an intrinsic property of relatively well developed sea. So according to fractal description of the sea surface the surface microscale $h \approx 1 \mathrm{~m}$ (Kolmogoroff's microscale) is in good agreement with the values of transitional wave number $\mathrm{k}_{\mathrm{g}}$ and frequency $\omega_{\mathrm{g}}$ which appear indirectly in the Phillips (1985) and Banner et al. (1989) papers. Their results we'll reanalyze, but it seems from above said that it is instructive to establish the correspondence between Kitaigorodskii (1983) "transitional" scales and fractal model of the sea with its inner microscale $\mathrm{h}$. We'll discuss this topic later on, as well as the assumption about the separation of the region of energy input from wind and dissipation due to wave breaking in the high-frequency, high wave number parts of wave spectra.

1. Statistical equilibrium, saturation, and dissipation subrange in wind wave spectra

\subsection{Spectral characteristics of wind wave field}

The rather complete description of the commonly used spectral characteristics of wave field, which are either measurable or calculable can be found in the papers of Kitaigorodskii (1987) and Banner (1990). Both contain a good account of the spectral description of random wind wave field. We briefly repeat here what in this respect will be needed for further discussions.

The Fourier series representation of the surface $\zeta(x, t)$.

$$
\zeta(\mathrm{x}, \mathrm{t})=\left(\int \int \operatorname { e x p } \left\{\mathrm{i}(\mathrm{kx}-\omega \mathrm{t}) \mathrm{d} \mathrm{Z}_{\zeta}(\mathrm{k} \omega)=\int \mathrm{dk} \int \mathrm{d} \omega \zeta_{\mathrm{k} \omega} \exp \{\mathrm{i}(\mathrm{kx}-\omega \mathrm{t})\}\right.\right.
$$

$\left\{\mathrm{k}=\left(\mathrm{k}_{1}, \mathrm{k}_{2}\right)=(\mathrm{k} \cos \vartheta, \mathrm{k} \sin \vartheta)\right.$ is wave number vector, $\omega$ is frequency $\}$ is often used in the description of random wave field (in this case $\mathrm{dZ}_{\zeta}(\mathrm{k}, \omega)$ is Fourier-Stilties amplitude).

The symmetrical wave spectrum $\mathrm{E}_{\mathrm{s}}(\mathrm{k}, \omega)$ defined as

$$
\mathrm{E}_{\mathrm{s}}(\mathrm{k}, \omega)=\mathrm{E}_{\mathrm{s}}(-\mathrm{k},-\omega)=<\zeta_{\mathrm{k} \omega} \zeta_{\mathrm{k} \omega} *>
$$

is the Fourier transform of the covariance B $(r, \tau)$

$$
E_{s}(k, \omega)=(2 \pi)^{-3} \int d r \int d \tau B(r, \tau) \exp \{-i(k r-\omega \tau)\}
$$

with normalization condition

$$
<\zeta^{\mathrm{z}}>=\mathrm{B}(0,0)=\int \mathrm{dk} \int \mathrm{d} \omega \mathrm{E}_{\mathrm{s}}(\mathrm{k}, \omega)
$$

and

$$
\mathrm{B}(\mathrm{r}, \tau)=\mathrm{B}(\mathrm{x}+\mathrm{r}, \tau, \mathrm{x}, \mathrm{t})
$$


The reduced symmetrical (measurable) wave number spectra $\psi_{\mathrm{s}}(\mathrm{k})$ and frequency spectra $S(\omega)$ can be obtained by integration over $\omega$ and over $k$

$$
\begin{aligned}
& \psi_{\mathrm{s}}(\mathrm{k})=\int \mathrm{d} \omega \mathrm{E}_{\mathrm{s}}(\mathrm{k}, \omega) \\
& \mathrm{S}_{\mathrm{s}}(\omega)=\int \mathrm{dk} \mathrm{E}_{\mathrm{s}}(\mathrm{k}, \omega)
\end{aligned}
$$

$\psi_{\mathrm{s}}(\mathrm{k})$ arises from frozen spatial image analyses and does not contain actual wave propagation information partitioning the wave energy equally to components $180^{\circ}$ apart.

Note, (Kitaigorodskii, 1986) that

$$
\psi_{\mathrm{s}}(\mathrm{k})=1 / 2[\mathrm{~F}(\mathrm{k})+\mathrm{F}(-\mathrm{k})]
$$

where the directional wave number spectrum $F(k)$ is defined as

$$
1 / 2 \mathrm{~F}(-\mathrm{k}) \delta\left(\mathrm{k}-\mathrm{k}{ }^{\prime}\right)=<\eta_{\mathrm{k}}{ }^{-}\left(\eta_{\mathrm{k}}{ }^{-}\right)^{*>}
$$

where in (1)

$$
\zeta_{\mathrm{k} \omega}=\eta_{\mathrm{k}}^{+} \delta(\omega-\delta)+\eta_{\mathrm{k}}^{-} \delta(\omega+\delta)
$$

and random coefficients $\eta_{\mathrm{k}}{ }^{+}, \eta_{\mathrm{k}}{ }^{-}$are the amplitudes of free linear surface gravity waves propagating in the positive and negative direction of the vector $k$, and satisfies the dispersion relationship for surface waves. That is why for a weakly nonlinear wave field the Fourier series representation (1) is a more natural tool for theoretical analyses than in studies of turbulent random fields. The directional wave number spectrum $\mathrm{F}(\mathrm{k})$

$$
F(k)=2 \int_{\infty}^{\infty} E_{s}(k, \omega) d \omega
$$

represents the actual wave number distribution of wave energy.

$$
\begin{aligned}
& \varphi_{\mathrm{s}}\left(\mathrm{k}_{1}\right)=\int_{\infty}^{\infty} \psi_{\mathrm{s}}\left(\mathrm{k}_{1}, \mathrm{k}_{2}\right) \mathrm{dk}_{2} \\
& \varphi_{\mathrm{s}}\left(\mathrm{k}_{2}\right)=\int_{\infty}^{\infty} \psi_{\mathrm{s}}\left(\mathrm{k}_{1}, \mathrm{k}_{2}\right) \mathrm{dk}_{1}
\end{aligned}
$$

and among the calculated reduced spectra, the spectrum of wave number module, characterizing energy distribution over $\mathrm{k}$ regardless of the direction of wave propagation defined as 


$$
\chi(\mathrm{k})=\int_{|\mathrm{k}|=\mathrm{k}} \psi_{\mathrm{s}}(\mathrm{k}) \mathrm{dk}=\int_{-\pi}^{+\pi} \psi_{\mathrm{s}}(\mathrm{k}, \theta) \mathrm{d} \theta
$$

or the spectrum $\mathrm{F}_{\mathrm{k}}$ averaged over all directions of wave propagation

$$
F_{k}=\int F(k) d \theta=\int_{-\pi}^{+\pi} F(k, \theta) d \theta
$$

It is evident from (8-16) that to calculate the reduced spatial spectra $(13,16)$ we need either a model for directional wave number spectra $F(k)$, or the empirical description of the whole 2-dimensional symmetrical spectra $\psi_{\mathrm{s}}(\mathrm{k})$.

Now, we'll try below to introduce the noncontroversial definitions of what is considered in the literature as equilibrium spectra (or equilibrium range in wave spectra), saturation (or saturation range in wave spectra), and finally what we'll call dissipation subrange in wind wave spectra.

\subsection{The definitions of equilibrium and quasi-equilibrium range in wind wave} spectra

The evolution of the directional wave number spectrum $F(k, x, t)$ has been described by the so-called radiative transfer equation

$$
\mathrm{DF}(\mathrm{k}) / \mathrm{Dt}=\partial \mathrm{F}(\mathrm{k}) / \partial \mathrm{t}+\mathrm{C}_{\mathrm{g}} \nabla \mathrm{F}(\mathrm{k})=\mathrm{S}_{\mathrm{in}}(\mathrm{k})+\mathrm{S}_{\mathrm{nl}}(\mathrm{k})+\mathrm{S}_{\mathrm{diss}}(\mathrm{k})
$$

Here $S_{\text {in }}(k), S_{n l}(k)$ and $S_{\text {diss }}(k)$ are the so called "source" terms, representing the spectral distributions of wind input, nonlinear interactions between wave components, and dissipation through wave breaking and wave-turbulence interactions. If for certain ranges of $k(k, \theta)$

$$
\mathrm{DF} / \mathrm{Dt}=\partial \mathrm{F} / \partial \mathrm{t}+\mathrm{C}_{\mathrm{g}} \nabla \mathrm{F}=0
$$

such a region can be called an equilibrium range of $F(k)$, and corresponding form of $F$ (k) spectra in this region equilibrium spectra. In practice we of course deal with the situation when in certain part of $\mathrm{k}$ domain

$$
\mathrm{DF} / \mathrm{Dt}<<\mathrm{S}, \text { where } \mathrm{S}=\mathrm{S}_{\mathrm{nl}}+\mathrm{S}_{\text {in }}+\mathrm{S}_{\text {diss }}
$$

what means that this part of the spectrum is in quasi-equilibrium. The condition (19a) seems to be fulfilled in fetch growth situation not only for major parts of rear faces of wind wave spectra, but also for whole energy containing region and that is why the similarity descriptions of wind wave development according to Kitaigorodskii scaling (Kitaigorodskii, 1962), are both applicable and successful in the prediction of the 
growth of wind wave field with fetch (for overall characteristics like energy, mean wave period, significant wave height and so on).

\subsection{What is so called saturation form of wind wave spectra?}

The most general analyses of equilibrium spectra of the type $(18,19)$ was done by Phillips (1985), who used the dimensional arguments (selfsimilarity) in description of $\mathrm{S}_{\mathrm{diss}}$ and assumption about the equality by the order of magnitude of all source terms in (17). Later on, Banner (1990) prefer to rely on the pure empirically chosen canonical form of 2-D $\psi_{\mathrm{s}}(\mathrm{k})$ in the equilibrium range of $\psi_{\mathrm{s}}(\mathrm{k})(19)$, disagreeing partially both with Kitaigorodskii (1983) and Phillips (1985) descriptions of equilibrium conditions. He put special attention to the role of k-dependent form of angular distribution of energy in equilibrium part of $\psi_{\mathrm{s}}(\mathrm{k})$. The fact that we must talk about an equilibrium not only with respect to $k$, but also to $\theta$, i.e. about certain region $(k, \theta)$ in the spatial spectrum $\psi_{\mathrm{s}}(\mathrm{k})$, was first pointed out in Kitaigorodskii et al. (1975) in their discussion of the Phillips (1958) hypothesis about the special form of spectra, derived on the basis of formation of "wedges", i.e. sharp wedge type crest for each wave.

It is the form of the spectra predicted by Phillips (1958) using the latter idea

$$
\psi_{\mathrm{s}}(\mathrm{k}, \theta)=\mathrm{Bk}^{-4} \zeta(\theta)
$$

which was later on called a saturation form, and the corresponding range of $(\mathrm{k}, \theta)$ saturation range of wind-wave spectra. As the boundaries of such range in $k, \theta$ plane are not known a priori, no unambiguous conclusions about the shape of the $\psi\left(\mathrm{k}_{1}\right), \psi$ $\left(\mathrm{k}_{2}\right)$ or $\chi(\mathrm{k})$ spectra can be drawn even if the function in (20) (satisfying the standard normalization condition $\left.\int_{-\infty}^{+\infty}=\zeta(\theta) \mathrm{d} \theta=1\right)$ is known, unless one makes some additional assumptions not following from the similarity arguments itself, such as for instance one utilized by Phillips (1966) who assumed that in (20)

$$
\zeta<\theta>=\left\{\begin{array}{l}
1 / \pi|\theta| \leq \theta_{\mathrm{m}}=\pi / 2 \\
0|\theta|>\theta_{\mathrm{m}}
\end{array}\right.
$$

where $\theta_{\mathrm{m}}$ corresponds to the dominant wave direction. However to some extent the general form of Eq. (20) contradicts the data of the most detailed investigation of angular energy distribution in the wave spectrum, as obtained by Longuet-Higgins et al. (1963), Ewing (1969) and most recently in a comprehensive study of Donelan et al. (1985). It seems that k-independence of angular distribution and the lack of sensivity to both wind strength and wind direction (tendency to isotropy), as in $(20,21)$, can be observed only for shortest wave components (see for example Banner et al. 1989). Because of this both in Kitaigorodskii et al. (1975) and Kitaigorodskii (1983), the physical hypothesis about the statistical characteristics of wave field, has been formulated to those which were already averaged over all directions of wave 
propagation, i.e., directly to the spectra $\chi(\mathrm{k})$ or $\mathrm{F}_{\mathrm{k}}$ as it is done often in the theory of small scale axisymmetric turbulence. One of the reasons why k-independent type of angular distribution, including isotropy, is of particular interest in deriving the average (over all angles) wave statistics is due to the fact that the very special type of statistical equilibrium in weakly nonlinear field of surface gravity waves can be described by particular form of equation (17)

$$
\mathrm{S}_{\mathrm{nl}} \equiv 0
$$

which is known as wave kinetic equation.

\subsection{The different types of spectral energy balance for equilibrium spectra}

The forms of equilibrium spectra corresponding to (22) for statistically averaged characteristics was first derived by Kitaigorodskii (1983). For isotropic wave field the exact analytical solution of (22) was studied by Zakharoff and Filonenko (1966). Later on in the series of papers by Zakharoff and Zaslavskii $(1982,1983)$ it was shown that (22) leads to two special forms of Kolmogoroff's type cascade spectra $F_{k}$ (Kitaigorodskii, 1987). One of them based on action flux towards low wave numbers were successfully applied for the description and parametrization of wave field in the case of the so called fully developed waves (sea also Zakharoff, 1992). We'll not consider the fully developed wind wave spectra as an example of equilibrium spectra, leaving the latter name just for range of wave numbers (and frequencies) at least larger than the peak wave number $\mathrm{k}_{\mathrm{p}}$ (or frequency $\omega_{\mathrm{p}}$ ).

Finally let us introduce like In Kitaigorodskii (1983) and Hansen et al. (1990) the definition what can be called - the dissipation subrange in wind wave spectra. According to these authors this is the range of wave numbers $\mathrm{k} \geq \mathrm{k}_{\mathrm{g}}$ where two conditions are satisfied simultaneously

$$
\mathrm{S}_{\mathrm{nl}}(\mathrm{k})=0 \text { for } \mathrm{k}_{\mathrm{g}} \leq 0
$$

and

$$
\mathrm{S}_{\mathrm{nl}}(\mathrm{k})-\mathrm{S}_{\mathrm{diss}}(\mathrm{k})=0 \text { for } \mathrm{k} \geq \mathrm{k}_{\mathrm{g}}
$$

Here it is assumed that the wind energy input is negligible not only near the transitional wave number $\mathrm{k}_{\mathrm{g}}$ but for some range of $\mathrm{k}<\mathrm{k}_{\mathrm{g}}$ and that wave breaking become a dominant mechanism at wave numbers higher that the wave number $\mathrm{k}_{\mathrm{g}}$ of gravitational instability (which supposedly is much higher than $\mathrm{k}_{\mathrm{p}}$ ) and can depend also on direction $\theta$. The basic role of weak nonlinear interactions is then in redistributing energy from the range of $\mathrm{k} \leq \mathrm{k}_{\mathrm{p}}$ (Kitaigorodskii, 1983; Zakharoff and Zaslavskii, 1982) to dissipation $\mathrm{k} \geq \mathrm{k}_{\mathrm{g}}$ in such a way that nonlinear divergence of energy in the range $\mathrm{k}_{\mathrm{p}} \leq$ $\mathrm{k} \leq \mathrm{k}_{\mathrm{g}}$ is in balance with wind energy input $\mathrm{S}_{\mathrm{in}}$ in a stationary wave field (Phillips, 
1985). Here by $k_{g}$ it is worthwhile to understand the average value $k_{g}=\int k_{g}(\theta) d \vartheta$ so that angular distribution can weight towards $\mathrm{k}_{\mathrm{g}}$ in usual way through isotropic dispersion relationship $\left(\omega_{\mathrm{g}}=\left(\mathrm{g} \mathrm{k}_{\mathrm{g}}\right)^{1 / 2}\right.$ (if Doppler shifting is not taken into account).

According to equation (23) it can exist a direct energy cascade towards smaller scales which can cause small scale wave breaking (Zakharoff, 1992); such definition of the dissipation subrange means that in wave number (or frequency) domain the subrange have to occur as a more rapid spectral fall-off compare with one in equilibrium range of wave spectra, and that without the latter there will be no dissipation subrange, if we accept the above introduced terminology. According to this terminology. $S_{n l}(k) \cong S_{\text {inp }}(k)$ in the equilibrium range of the spectra, whereas $S_{n l} \cong S_{\text {in }}$ $=\mathrm{S}_{\mathrm{diss}}$, is just a particular type of statistical equilibrium, like in the Kolmogoroff's type of theory of the inertial subrange of quasi-isotropic turbulence, where the dissipation subrange due to the direct action of molecular viscosity is introduced in high wave number part of the spectra.

The weak point of such definitions is of course a neglect of the fact that in some of the situations the real observed wind wave spectra in energy containing region for anisotropic field of waves simply have a "saturation" (20) (Banner, 1990).

The form of the spectra in equilibrium range can be derived either from a asymptotic arguments of domination of direct energy cascade (for isotropic field Zakharoff, 1992) which can produce both small scale wave breaking and fractalization of the sea surface, or from balance of source term like in Phillips (1985), where dissipation and weakly nonlinear interaction was assumed to be of the same order which again means that small scale wave breaks. The equilibrium spectra have the form $\omega^{-4}$ or $\mathrm{k}^{-7 / 2}$ (Kitaigorodskii. 1983).

\subsection{The transitional scales for dissipation subrange in wind wave spectra}

Phillips (1958) first constructive idea about the sharp crests wave became well known as hypothesis about the saturation of wave components due to the limitation imposed on their growth by breaking process. For frequency spectra it gives simple and very elegant result

$$
S(\omega)=\beta g^{2} \omega^{-5}
$$

where $\beta$ is nondimensional universal constant which at least two order of magnititude is less then 1 . It becomes very evident from the latest data analyses that attempts to apply Phillips spectrum to energy containing but still rear face of the spectrum are unsatisfactory. It seems that only after Kitaigorodskii (1983) suggestion to consider $(24,25)$ as an asymptotic form of the dissipation subrange in the quasyequilibrium wave spectra, it becomes clear that Phillips (1958) strongly nonlinear sharp crests spectrum model must be revisited in favor of the existence of an intrinsic "inner scale" of the sea surface on analogy with Kolmogoroff's inner scale in 3-D turbulence. 
Such inner scales can appear in wave data analyses as transitional wave number $\mathrm{k}_{\mathrm{g}}$ (or frequency $\omega_{\mathrm{g}}$ ), and it becomes customary to consider the deviation from new equilibrium form (Kitaigorodskii. 1983, Phillips, 1985) or from direct energy cascade form, to be associated with domination of gravitational instability (wave breaking), over all other processes, like viscosity or surface tension (Zakharoff, 1992), and therefore with transition to the dissipation subrange in wave field. In the next two sections I'll discuss the experimental data about spatial and temporal statistical characteristics of wind wave field with the purpose to indicate such transition and interpret it as an evidence of the existence of dissipation subrange in wind wave spectra. The very existence of this subrange is just the indication where wave breaking begin to dominate the form of the spectra.

2. Wave breaking and it's influence on the nonlinear direct energy cascade in wind wave field

2.1. The region of applicability of direct nonlinear energy cascade in the wind-wave field and isotropization of the wave field

In 2-D wavenumber space let us first restrict our attention to wave numbers well below those associated with capillary ripples and (those) directly influenced by viscosity, so that

$$
\mathrm{k}<<\mathrm{k}_{\mathrm{T}}=\left(\rho_{\mathrm{w}} \mathrm{gT}^{-1 / 2}\right) ; \quad \mathrm{k}<<\mathrm{k}_{\mathrm{v}}=\mathrm{g}^{1 / 4} \mathrm{v}^{-1 / 2}
$$

( $\mathrm{T}$ is surface tension, $v$ is kinematic viscosity, and $\rho_{\mathrm{w}}$ is density of sea water), and also well above those $\mathrm{k}$ which are associated with the strong direct energy input from wind, $\mathrm{k}=\mathrm{k}_{\mathrm{in}} \geq \mathrm{k}_{\mathrm{p}}$, where $\mathrm{k}_{\mathrm{p}}$ is wave peak number, so that

$$
\mathrm{k}>>\mathrm{k}_{\mathrm{p}}=\omega_{\mathrm{p}}^{2} \mathrm{~g}^{-1}
$$

Then we can expect that somewhere in the region (26-27) the wind wave field loses its directionality (the function $\mathrm{k}_{\mathrm{in}}=\mathrm{k}_{\mathrm{in}}(\theta)$ must have a clearly defined maximum at $\theta=\theta_{\mathrm{m}}$, where $\theta_{\mathrm{m}}$ coincides with the wind direction or the direction of dominant wind waves propagation). We would assume for moment that there must exist the spreading cut off on scale much shorter than $\mathrm{k}_{\mathrm{in}}$, (where the angular distribution approaches isotropy).

According to Banner (1990), the spreading cut off is still unlikely to occur at k/ $\mathrm{k}_{\mathrm{p}}$ $\leq 2,6$ (as was initially suggested in Donelan et al. (1985)) and is expected to be on much shorter scales (Banner et al., 1989). Figure 2 in Banner (1990) shows the spreading cut off occurs approximately at $\mathrm{k} / \mathrm{k}_{\mathrm{p}} \geq 9-10$. Even though these numbers cannot be immediately transferred to the frequency domain range (Doppler shift), it is useful to remember that $\mathrm{k} / \mathrm{k}_{\mathrm{p}} \sim 10$ roughly gives $\omega / \omega_{\mathrm{p}}=3$ as the lower (in frequency) boundary of the region where the wave field loses its directionality (at least 
qualitatively). In reality it seems that the spreading cut off occurs at wave number higher than $\mathrm{k} / \mathrm{k}_{\mathrm{p}} \sim 10$.

Following Zakharoff and Zaslavskii's $(1982,1983)$ applications of the theory of weakly nonlinear surface gravity waves to the analyses of wind wave data the case of well-developed waves must correspond to $k_{p}=(2 \approx 4) g / U_{a}^{2}, U_{a}$ is wind speed, with the corresponding region of the energy input

$$
\mathrm{k}_{\mathrm{inp}} \approx(4-6) \mathrm{g} / \mathrm{U}_{\mathrm{a}}^{2}=(2-3) \mathrm{k}_{\mathrm{p}}
$$

Thus, we can see that in the wave number space there can exist at least a narrow region

$$
(9-10) \mathrm{k}_{\mathrm{p}} \geq \mathrm{k} \geq(2-3) \mathrm{k}_{\mathrm{p}} \approx \mathrm{k}_{\mathrm{inp}}
$$

where in spite of the directionality of the wave field the nonlinear interactions can still play a major role both in redistributing energy between directions and in giving rise to smaller-scale waves, as well as inducing small-scale wave breaking (Zakharoff, 1992). However, it must not be forgotten that in this region both the directionality and wave age dependence (at least parametrically) can influence the description of 2-D wavefield characteristics. This was demonstrated in Banner (1990), who simply accepted the Donelan et al. (1985) empirical model of wave spectra with their angular distribution, extrapolated to high wave numbers.

The region described in (28-29) is characterized by strong directionality and symmetry relative to the direction of dominant waves (or mean wind direction). However, (29) can still be called an equilibrium range of wind-wave spectra contrary to the Phillips (1985) and Banner (1990) models, and the similarity hypothesis can be applied here to statistically averaged characteristics of the wave field. The end of this equilibrium range, which can identify the transfer to a region where dissipation due to wave breaking becomes a dominant process (i.e., dissipative part of spectra), depends on angle. We will define this end as $\mathrm{k}_{\text {bound: }}$ :

$$
\mathrm{k}_{\mathrm{bound}}=\mathrm{k}_{\mathrm{diss}}(\vartheta)
$$

We will also use an effective value $\mathrm{k}_{\mathrm{g}}$ :

$$
\mathrm{k}_{\mathrm{g}}=\int_{\theta} \mathrm{k}_{\mathrm{diss}}(\theta) \mathrm{d} \theta
$$

Then the transitional frequency $\omega_{\mathrm{g}}$ between the essentially nondissipative part of the equilibrium range and the strongly dissipative part can be defined as

$$
\omega_{\mathrm{g}}=\sqrt{ } \mathrm{gk}_{\mathrm{g}}
$$

This $\omega_{\mathrm{g}}$ (defined through $\mathrm{k}_{\mathrm{g}}$ ) must be close but not necessarily equal to the experimentally derived transitional frequency $\omega_{\mathrm{g}}$ as the beginning of the rapid spectral 
cut off on the rear face of frequency spectra, associated with an asymptotic approach to the saturation form (see (3) below).

How to estimate $\omega_{\mathrm{g}}$ ? Since the description of the wind wave interaction invariably includes a small parameter $\varepsilon=\rho_{\text {air }} / \rho_{\text {water }} \approx 10^{-3}$, typical scales of energy containing weakly nonlinear waves in a developed sea can be estimated as $k_{\text {nonlin }} \approx g / U_{a}{ }^{2}$. In this case the motion is smooth and can be considered as superposition of weakly nonlinear waves. The level of nonilnearity depending on slope growth with increase of wavenumber. On some small scales the direct cascade of energy due to weak nonlinear interactions can produce small-scale wave breaking (Kitaigorodskii, 1983; Zakharoff, 1992) and first fractalization of the sea surface. To estimate such transition, Zakharoff suggested to put $\mathrm{k}_{\text {trans }} \approx \varepsilon \mathrm{k}_{\text {nonlin }} \approx \varepsilon\left(\mathrm{U}_{\mathrm{a}}{ }^{2} / \mathrm{g}\right)$. For wind speed of $10 \mathrm{~m} / \mathrm{s}$ this gives $\lambda_{\text {trans }}=$ $2 \pi / \mathrm{k}_{\text {trans }} \cong 6 \mathrm{~cm}$. Of course, the process of wave breaking can be observed only when smoothing factors such as viscosity and surface tension are unimportant, i.e.

$$
\mathrm{k}_{\text {trans }}<\left\{\begin{array}{l}
\mathrm{k}_{\mathrm{T}} \\
\mathrm{k}_{\mathrm{v}}
\end{array}\right.
$$

However, $\mathrm{k}_{\text {trans }}$ can not be identified with transitional scales $\mathrm{k}_{\mathrm{g}}$ and $\omega_{\mathrm{g}}$, introduced in spectral language, for two reasons: first, real spectra have a small parameter $\varepsilon^{1 / 2} \approx 3 \cdot 10^{-}$ ${ }^{2}$; second, the weak nonlinear interactions, leading to small-scale wave breaking and fractalization of the sea surface, produced $\mathrm{k}^{-7 / 2}$ and $\omega^{-4}$ forms of the spectrum (Kitaigorodskii, 1983), rather than the nonlinear Phillips $\mathrm{k}^{-4}$ or $\omega^{-5}$ spectra (that is why Phillips constants $\beta$ and B are much smaller than unity, actually $0\left(10^{-2}\right)$, when they are derived from real data (Zakharoff, 1992)). If the Phillips constant was about unity, this would have mean that each wave has a sharp wedge-type crest, and this will would have been picture of developed wave breaking. Probably this has never been observed. Therefore, the transition from the $\mathrm{k}^{-7 / 2}$ and $\omega^{-4}$ forms of the spectra to the more rapid spectral cut off what we'll call the transition to the dissipation subrange, means that in this subrange the dissipation of wave energy into turbulence (and then heat) is a dominant process, and neither wind energy input nor weak nonlinear interactions play any role. Zakharoff (1992) estimated the critical wind velocity for fractalization of the sea surface from the condition $\mathrm{k}_{\text {trans }} \leq \mathrm{k}_{\mathrm{T}}$, which leads him to $\mathrm{U}_{\mathrm{a}}{ }^{\mathrm{CR}} \approx 6 \mathrm{~m} / \mathrm{sec}$. This is not far from estimates obtained in the last paragraphs of this paper by using data on Kolmogoroff microscale in the wind-wave field. It is worthwhile to mention that the more rapid spectral fall-off than $\mathrm{k}^{-7 / 2}$ and $\omega^{-4}$, which in our definition, identify the transition to the dissipation subrange, means transfer from a fractal surface with one dimension to another type of fractal surface (with other dimension).

\subsection{The form of wind-wave spectra at high wave numbers and frequencies outside} the region of the direct input of wind energy

The general similarity hypothesis applied to the region 


$$
\left.\mathrm{k}_{\mathrm{v}}^{\mathrm{k}_{\mathrm{T}}}\right\}<\mathrm{k}<\mathrm{k}_{\text {inp }}
$$

must be based on the dependence of statistical characteristics of wind-wave field on the parameters $\mathrm{g}$, $\mathrm{k}$ ( or $\omega$ ), and $\varepsilon_{0}$, where $\varepsilon_{0}=\int \varepsilon(\theta) \mathrm{d} \theta$ is a constant energy flux from the region of the energy input through the nondissipative part of spectra towards high wave numbers. According: to this hypothesis, (Kitaigorodskii, 1983) for such characteristics as the energy spectrum $F_{k}$ and wave action spectral density $N_{k}=g F_{k} / \sigma(k)(\sigma=\sigma(k)$ is the isotropic dispersion relationship) we have the following expressions:

$$
\begin{aligned}
& \mathrm{F}_{\mathrm{k}}=\int \mathrm{F}(\mathrm{k}) \mathrm{d} \theta=\varepsilon_{0}{ }^{1 / 3} \mathrm{~g}^{-1 / 2} \mathrm{k}^{-7 / 2} \phi_{1}\left(\mathrm{k} / \mathrm{k}_{\mathrm{g}}\right) \\
& \mathrm{N}_{\mathrm{k}}=\int \mathrm{N}(\mathrm{k}) \mathrm{d} \theta=\varepsilon_{0}{ }^{1 / 3} \mathrm{k}^{-4} \phi_{2}\left(\mathrm{k} / \mathrm{k}_{\mathrm{g}}\right)
\end{aligned}
$$

In the essentially nondissipative range of spectral wave characteristics $\left(\mathrm{k} / \mathrm{k}_{\mathrm{g}}\right.$ " 1$)$, the nonlinear interactions would play a major role, and because they are cubic in, wave amplitude, it follows (Kitaigorodskii, 1983; Phillips, 1985) that

$$
\phi_{1}=\phi_{2}=\mathrm{A}
$$

where $\mathrm{A}$ is an absolute constant, supposedly close to unity. We define the dissipative subrange as a region where the governing parameters are those that determine continuity of the wave surface and therefore, asymptotically $F_{k}$ and $N_{k}$ become independent of $\varepsilon_{0}$, so that

$$
\phi_{1}\left(\mathrm{k} / \mathrm{k}_{\mathrm{g}}\right)=\phi_{2}\left(\mathrm{k} / \mathrm{k}_{\mathrm{g}}\right)=\mathrm{B}\left(\mathrm{k} / \mathrm{k}_{\mathrm{g}}\right)^{1 / 2} \text { as } \mathrm{k} / \mathrm{k}_{\mathrm{g}} \rightarrow \infty
$$

where B is another absolute constant. The asymptotic prediction (36) corresponds to the Phillips (1958) initial saturation form of the spectra, based on the idea of strongly nonlinear waves associated with sharp crests. Here it is based on the value

$$
\mathrm{k}_{\mathrm{g}}=\mathrm{Cg} / \varepsilon_{0}^{2 / 3}
$$

where $\mathrm{C}$ is another numerical constant not necessarily of the order of unity because the dissipative process associated with wave breaking is not well-defined (both physically and formally). However, it should be remembered that in the 2-D wave number space some of the values of $k_{\mathrm{g}}$, for example $\mathrm{k}_{\mathrm{g}}\left(\theta_{\max }\right)$, where $\theta_{\max }$ coincide with the direction of dominant waves, can be much smaller then $\mathrm{k}_{\mathrm{g}}$ (37). That is possibly one of the reasons why in the Banner (1990) model the wave number spectral density slice in the dominant wave direction have a well-defined range (36) throughout the entire region (29). This along with the modulation of the forms of the spectra $(33,36)$ by orbital peak velocities, permits Banner (1990) to get the $\omega^{-4}$ form of the frequency spectra close 
enough to the peak $\left(\omega / \omega_{\mathrm{p}}<4\right)$ (see Fig. 7 in Banner (1990), with the transition to the $\omega^{-5}$ form at $\omega_{\mathrm{g}}$ roughly satisfying (32), and the equality (Hansen et al., 1990)

$$
\omega_{\mathrm{g}} \cong \frac{\mathrm{B}}{\mathrm{A}} \cdot \mathrm{g} / \varepsilon_{0}^{1 / 3}
$$

Before making some refinements of the hypothesis (33-36) about the form of the spectral characteristics (see P. III below) we'll discuss the work, which recently has been made by Zaslavskii (1998) who have suggested a different approach, by regecting the assumption about the prevailing role of direct energy cascade for $\mathrm{k}>\mathrm{k}_{\max }$, and replacing it by the dominant role of energy input from wind in whole rear face of wave spectra.

\subsection{The "blocking interval" in wind wave spectra}

The simplest model of it was suggested by Phillips (1985) who assumes the equality (by order of magnitude) of all terms in energy balance, and special selfsimilar form for $\mathrm{S}_{\text {diss. }}$. This has been done in his attempt to revisit his earlier theory of saturation (1958) with $\omega^{-5}$ for frequency spectra by replacing it to $\omega^{-4}$ form, which at that time was favorable choice by experimentalists. However as we'll show in P. III of this paper the experimental data definitely indicate the existence of a transition from $\omega^{-n}(n<5)$ to $\omega^{-5}$ form in frequency spectra, and what is even more important, the similar in nature transition, occurs in wave number spectra. Recently Zaslavskii (1998) has been trying to explain such transition avoiding the assumption about the separation between region of energy input from wind and dissipation, assuming instead that on rear faces wave spectra must exist the blocking interval $\mathrm{k}>\mathrm{k}_{\mathrm{bl}}$ where $\mathrm{S}_{\mathrm{in}}=\mathrm{S}_{\text {diss }}$ as a consequence of inequality $\mathrm{S}_{\mathrm{nl}}<\mathrm{S}_{\mathrm{in}}$. In difference to Phillips (1985) he prefer not to parametrize dissipation but to use prescribed $S_{\text {in }}$ and the assumption $S_{n l}=0$, which permits to introduce again the fluxes of momentum and energy through the spectra as important parameters. In the latter range of wave numbers $\left(\mathrm{S}_{\mathrm{nl}}=0\right)$ the statistical equilibrium according to Zaslavskii (1998) must be connected not with a constant nonlinear energy flux (due to 4 wave interactions) (as in cascade theory of Kitaigorodskii (1983), Zakharoff and Zaslavskii (1982)) but rather with a constant momentum flux through the wave spectra at $\mathrm{k}>\mathrm{k}_{\mathrm{bl}}$ due to the presence of $\mathrm{S}_{\mathrm{in}}$ for $\mathrm{k}>\mathrm{k}_{\mathrm{bl}}$. The approximations which he used to describe this type of equilibrium permits him to find analytical form of wave spectra for weakly nonlinear waves: it gives $\mathrm{k}^{-11 / 3}$ dependence (instead of $\mathrm{k}^{-7 / 2}$ ) and $\omega^{-}$ $13 / 3$ (instead of $\omega^{-4}$ ) (notice the small difference between $\mathrm{k}^{-8 / 3}$ and $\mathrm{k}^{-5 / 2}$ ). These forms of spectra still permits to look for difference between this type of equilibrium, and Phillips spectra (with $\mathrm{k}^{-3}$ and $\omega^{-5}$ form). Zaslavskii (1998) was trying to show that on condition of constant momentum flux for $\mathrm{k} \geq \mathrm{k}_{\mathrm{bl}}$ it is possible to receive analytically the strongly nonlinear Phillips saturation form of the spectra. The transition from quasi equilibrium form of the spectra to its "saturation" form he relates now to the balance between 
energy input and dissipation. As it will be shown below (P. III) the data analysis favor the existence of rather noticeable transition from energy containing rear faces of spectra to Phillips spectra, which we defined before as a dissipation subrange.

However explanation of this transition still can be attributed either according to Zaslavskii (1998) concept of blocking interval where $\mathrm{S}_{\text {in }}=\mathrm{S}_{\mathrm{diss}}$, or according to Kitaigorodskii (1983) transition from nondissipative to dissipative part of the spectra due to energy flux towards high wave numbers. Even though Zaslavskii (1998) work opens the possibility to explain Phillips saturation form without using the asymptotic arguments in similarity considerations (dependence of wave spectra only on g), it is not to be forgotten that Zaslavskii (1998) approach is based on pure empirical description of wind energy input (extrapolating to high wave numbers and frequencies). Therefore it seems to me that assumption about the separation between the region of direct energy input and dissipation have at least the equal right to exist as a basis for explanation of the observed features of wind wave spectra (not to say that this is supported by some numerical calculation of wind wave energy balance indicating that the conditions of constant energy flux can exist, though in rather narrow region of the wave spectra above peak enhancement region (see for example Komen et al. (1984)).

The data analysis which we has been performed below is in fact independent on any assumptions about the energy and momentum balance on the rear faces of wave spectra. The data analysis only shows that all of the most reliable existing empirical data demonstrates the existence of the transition from one form of the spectra to the region where spectral fall-off is more strong. This observed transition must be taken into account both when empirical description of wave spectra is given, as well as for theoretical explanation of wind waves growth. As it was shown in my papers (Kitaigorodskii, 1983, 1987), there are very little evidence about the existence of the region of inverse energy cascade on the rear face of the wave spectra above peak enhancement region except for very developed waves. Therefore we prefer to consider those ranges of wave numbers and frequencies where in our opinion the statistical equilibrium is described as above $\left(\mathrm{S}_{\mathrm{nl}}+\mathrm{S}_{\mathrm{in}}-\mathrm{S}_{\text {diss }}\right)=0$, without inverse energy cascade from high to low wave numbers.

\section{Transition to dissipation subrange (experimental data)}

\subsection{Spatial characteristics of wind wave field}

\section{SWOP spectra}

Dealing with spatial characteristics, it is natural to start with the classical SWOP data (Cote et al., 1960). McLeish and Ross (1983), examining the relationships between spatial and frequency spectra for SWOP data, have assumed that the effect of the wind underlying current is evident. Following these authors, the SWOP results have spectral 
peak levels well below the level of standard limited fetch conditions. However, according to recalculations of Kitaigorodskii (1984), the normalized spectral densities $\mathrm{F}_{\mathrm{k}}$ have a clearly defined $\mathrm{k}^{-7 / 2}$ region. In the spectrum a transition to the $\mathrm{k}^{-4}$ form occurs at $\mathrm{k}_{\mathrm{g}}=3,2 \mathrm{k}_{\mathrm{p}}$ and $\mathrm{k}_{\mathrm{g}}=0,2 \mathrm{~m}^{-1}$, or at a fairly large $\lambda_{\mathrm{g}} \sim 30 \mathrm{~m}$. The latter value justifies the neglect of the Doppler shift effect by permanent drift currents even as strong as 1 $\mathrm{m} / \mathrm{s}$ and leads to the transitional frequency $\omega_{\mathrm{g}} \cong 1,78 \omega_{\mathrm{p}}$. For fully developed waves $\left(\mathrm{k}_{\mathrm{p}}\right.$ $\left.\approx(2 \div 4) \mathrm{g} / \mathrm{U}_{\mathrm{a}}{ }^{2}\right), \omega_{\mathrm{g}} \approx 1,78 \omega_{\mathrm{p}}$ corresponds to $\omega_{\mathrm{g}} \approx(2,5 \div 3,7) \mathrm{g} / \mathrm{U}_{\mathrm{a}}$, still close to but less than $4 \mathrm{~g} / \mathrm{U}_{\mathrm{a}}$. Such a relatively low value of $\omega_{\mathrm{g}}$ can also be explained by the neglect in Doppler shift of orbital peak velocities (Kitaigorodskii et al., 1975), because the equilibrium range of $\mathrm{k}^{-7 / 2}$ in SWOP spectra occurs at $\mathrm{k} / \mathrm{k}_{\mathrm{p}} \geq 1,3\left(\omega / \omega_{\mathrm{p}} \geq 1,14\right)$, which nearly excludes the peak enhancement region (in the frequency range $-\omega / \omega_{p}<1,3$ ). The latter leads Banner (1990) to the conclusion that the SWOP spectra $\psi\left(\mathrm{k}, \theta_{\mathrm{m}}\right) \approx$ $0,3 \cdot 10^{-4} \mathrm{k}^{-4}$ have a dissipative form at rather low wave numbers, and can easily give the $\omega^{-4}$ form of frequency spectra at $\omega / \omega_{\mathrm{p}}<3$ (due to the modulation by peak orbital velocities), even though the spectra at $\omega / \omega_{\mathrm{p}}<3$ is little affected by the Doppler shift with orbital velocities (this was established for $\mathrm{k}^{-4}$, but not for $\mathrm{k}^{-7 / 2}$. form). Thus, we can consider the SWOP integrated (reduced) spectra $F_{k}($ or $\chi(k))$ as an example of fetch limited spectra with $\mathrm{k}^{-7 / 2}$ nondissipative part of equilibrium with a rapid transition to the dissipation subrange at $\mathrm{k}_{\mathrm{g}}=3.2 \mathrm{k}_{\mathrm{p}}$, or, with a SWOP wind speed of $9 \mathrm{~m} / \mathrm{s}$, and $\mathrm{k}_{\mathrm{g}}=0,2$ $\mathrm{m}^{-1}, \mathrm{k}_{\mathrm{g}} \mathrm{U}_{\mathrm{a}}^{2} / \mathrm{g} \approx 1,65$. The latter value leads to $\omega_{\mathrm{g}} \mathrm{U}_{\mathrm{a}} / \mathrm{g} \approx 1,28$, which seems to disagree with observations by Kitaigorodskii (1986, 1987) and Hansen et al. (1990). It should also remembered that the above mentioned values of $\omega_{g} U_{a} / g \approx 2,5-3,7$ were based on the assumption that the SWOP spectrum was close to fully developed waves which is not the case $\left(k_{p}>(2-4) g / U_{a}^{2}\right)$ (see Table 1). Therefore, we can conclude that SWOP spectra, being considered as fetch growth spectra, can have a transition to the dissipation subrange in both wave number and frequency domains (!), at lower frequencies than those derived by Hansen et al. (1990) (see Table 1).

\section{Banner et al. (1989) 2-D wave number spectra}

The recent stereophotogrammetric analyses (Banner et al., 1989) produces the results which, according to the authors, do not support the wave number dependence predicted by the equilibrium spectra for the wavelength range $0,2-1,6 \mathrm{~m}$, in spite of the fact that these wave lengths appear to have preferred direction. In particular, the correlation with the wind direction is very low (only the fine-scale structure $\lambda<0,2 \mathrm{~m}$ seems to have obvious correlation with wind direction). Because of the spectral range of wave lengths partially covered by stereophotoanalysis in this work, we have decided to examine the data reported by Banner et al. (1989) more carefully, with the purpose studying the transition from the spatial equilibrium spectra to the dissipation subrange in the same way as was done in Kitaigorodskii (1984) with SWOP data. The range of the key parameter $\mathrm{U}_{\mathrm{a}}{ }^{2} \mathrm{k} / \mathrm{g}$ in Banner et al. (1989) was $(1,75-100) \cdot 10^{3}$. Wind speeds 
were from 5,5 to $13,3 \mathrm{~m} / \mathrm{s}$. With an average value of the drag coefficient of $10^{-3}$, this corresponds to the range of nondimensional wave numbers $\mathrm{k} \mathrm{U}_{*}^{2} / \mathrm{g}=1,6-90\left(\mathrm{U}_{*}\right.$ friction velocity), which is basically the range of wave numbers on the rear face of relatively well-developed waves $\left(\mathrm{k}>\mathrm{k}_{\mathrm{p}}\right)$. Figure 4 in Banner et al. (1989) summarizes the results of four experiments and serves as a proof of the saturation in this range of scales. (Within the 95\% confidence limits, there is no observational support for the linear dependence on $U_{*}$, implied by equilibrium spectra). While relating the wind speed at $54 \mathrm{~m}$ (at an oil platform) to the surface friction velocity $\mathrm{U}_{*}$, is not straightforward, we still consider the values $\mathrm{k}_{\mathrm{g}} \mathrm{U}_{*}{ }^{2} / \mathrm{g} \sim 2-90$ to be reliable estimates of the conditions of the open-sea wind waves, measured in Banner et al. (1989). A closer look at the data presented in Figure 4 leads us to the following conclusions. In exp. 3, whose conditions are similar to Hansen et al. (1990), there is evidence of the more rapid spectral cut off at approximately $\mathrm{kU}_{*}{ }^{2} / \mathrm{g}=2 \cdot 10^{-2}$. We would like to interpret this as a transition from equilibrium $\mathrm{k}^{-7 / 2}$ to the dissipation subrange. At a wind speed of 5,5 $\mathrm{m} / \mathrm{s}$ the corresponding $\mathrm{U}_{*}$ equals $\approx 20-22 \mathrm{~cm} / \mathrm{s}$ (Kitaigorodskii and Donelan, 1984), which for the transitional wave number $\mathrm{k}_{\mathrm{g}}$ gives $\mathrm{k}_{\mathrm{g}} \mathrm{U}_{\mathrm{a}}{ }^{2} / \mathrm{g} \approx 9-12$ or $\omega_{\mathrm{g}} \mathrm{U}_{\mathrm{g}} / \mathrm{g} \approx 3-4$. This is close to the transitional characteristics reported by Kitaigorodskii (1987), Hansen et al. (1990).

In exp. 4 with a speed of $13,3 \mathrm{~m} / \mathrm{s}$ the transitional wave number $\mathrm{U}_{*}{ }^{2} \mathrm{k}_{\mathrm{g}} / \mathrm{g}$ is as high as (5-6) $10^{2}$ (this value was also taken from Figure 4 in Banner et al., 1989), thus leading, with a drag coefficient of $1,5 \cdot 10^{-3}$, to $\mathrm{k}_{\mathrm{g}} \mathrm{U}_{\mathrm{a}}{ }^{2} / \mathrm{g} \approx 31-40$ and, hence to $\omega_{\mathrm{g}} \mathrm{U}_{\mathrm{a}} / \mathrm{g}$ $\approx 5,5-6,3$, which is much higher than in exp. 3 . However, the wave age in exp. 4 is about half as small as that in exp. 3, which indicates that the transitional wave number and frequency move to lower values as waves develop, in agreement with Kitaigorodskii (1983) and Hansen et al. (1990). The dominant wave period $\mathrm{T}_{\mathrm{d}}$ in exp. 3, $\mathrm{T}_{\mathrm{d}}=6,6$ sec., leads to $\omega_{\mathrm{p}} \mathrm{U}_{\mathrm{a}} / \mathrm{g} \approx 0,16<<\frac{\omega_{\mathrm{g}} \mathrm{U}_{\mathrm{a}}}{\mathrm{g}} \sim 3-4$, which means that in this case there is enough space for the equilibrium $\mathrm{k}^{-7 / 2}$ spectra still above the peak enhancement region. The same can be roughly said of exp. 4 , where $T_{d}=5,5 \mathrm{sec}$ leads to $\omega_{\mathrm{d}} \approx 1,54 \mathrm{~g}$ / $U_{a}$, which is still at least one-third the value of $\omega_{g}$, so in exp. 4 there is also indirect evidence of the existence of $\mathrm{k}^{-7 / 2}$ equilibrium range with a transition to the dissipation subrange. In both cases $\omega_{\mathrm{d}}=2 \pi / \mathrm{T}_{\mathrm{d}} \approx \omega_{\mathrm{p}}$ (Banner, personal communication).

The conditions of exp. 2 were characterized by strong winds and white capping that is possibly why Figure 4 in Banner et al. (1989) shows no indication of the transition, since the dissipation subrange can occupy the entire domain of observed wave numbers (as well as in exp. 1). Indeed, the description of experiments in Banner et al. (1989) (see their Table 1 and 2) indicates that only exp. 3 and 4 correspond to relatively steady conditions, they both show some evidence of the transition to the dissipation subrange, which agrees with the calculations in Hansen et al. (1990) of the movement of $\omega_{\mathrm{g}}$ toward a lower frequency with wave growth (either with fetch or duration). 


\section{Lupyan - Sharkov (1989) wave number spectra}

This is a very interesting study where in Caspian Sea for 50-250 km fetches and wind speed $U_{10} \cong 6,2 \mathrm{~m} / \mathrm{s}$ the 2-D wavenumber spectra were measured from planes by the aerofoto-graphic method. The conditions roughly corresponds to the growth of waves at large fetches. The wave number range where this method was permitted to describe the sea surface, was $0,3 \mathrm{~m}^{-1}-12 \mathrm{~m}^{-1}$. Figure 5 of Lupyan and Sharkov (1989) shows that the more rapid spectral cut off occurs at about $\mathrm{k} \cong 1,8-2,0 \mathrm{~m}^{-1}$. At smaller wave numbers the spectral shape is close to $\mathrm{k}^{-3}$, which is not too far from the equilibrium direct energy cascade $\mathrm{k}^{-7 / 2}$ form. It is possible to show that the latter range is still outside the region of inverse energy cascade, which can occur at $\mathrm{k}=\mathrm{k} \mathrm{U}_{\mathrm{a}}{ }^{2} / \mathrm{g}<$ $1,5 \div 2$. Provided the transitional wavenumber $\mathrm{k}_{\mathrm{g}}$ lies within $1,8-2,0 \mathrm{~m}^{-1}\left(\mathrm{k}_{\mathrm{g}} \mathrm{U}_{\mathrm{a}}^{2} / \mathrm{g} \approx\right.$ $7,06-7,84)$, this leads to the transitional frequency $\omega_{\mathrm{g}} \mathrm{U}_{\mathrm{a}} / \mathrm{g} \approx 2,65-2,80$, lower than the usually accepted value. However, it must be remembered that these data correspond to large nondimensional fetches or small values of $U_{a} / C_{p}$, so we will see that they are consistent with the other data (Figure 1). It is also interesting to note from their Figure 5 that at large wave numbers $\left(\mathrm{k}=2-92 \mathrm{~m}^{-1}\right)$, where the Phillips (1958) form of spectra is a good approximation, the clear isotropization of 2-D wave number spectra is observed even for fetches under consideration $(\mathrm{X} \cong 150 \mathrm{~km})$. Thus the data of Lupyan and Sharkov (1989) can be considered as good evidence of the existence of the dissipation

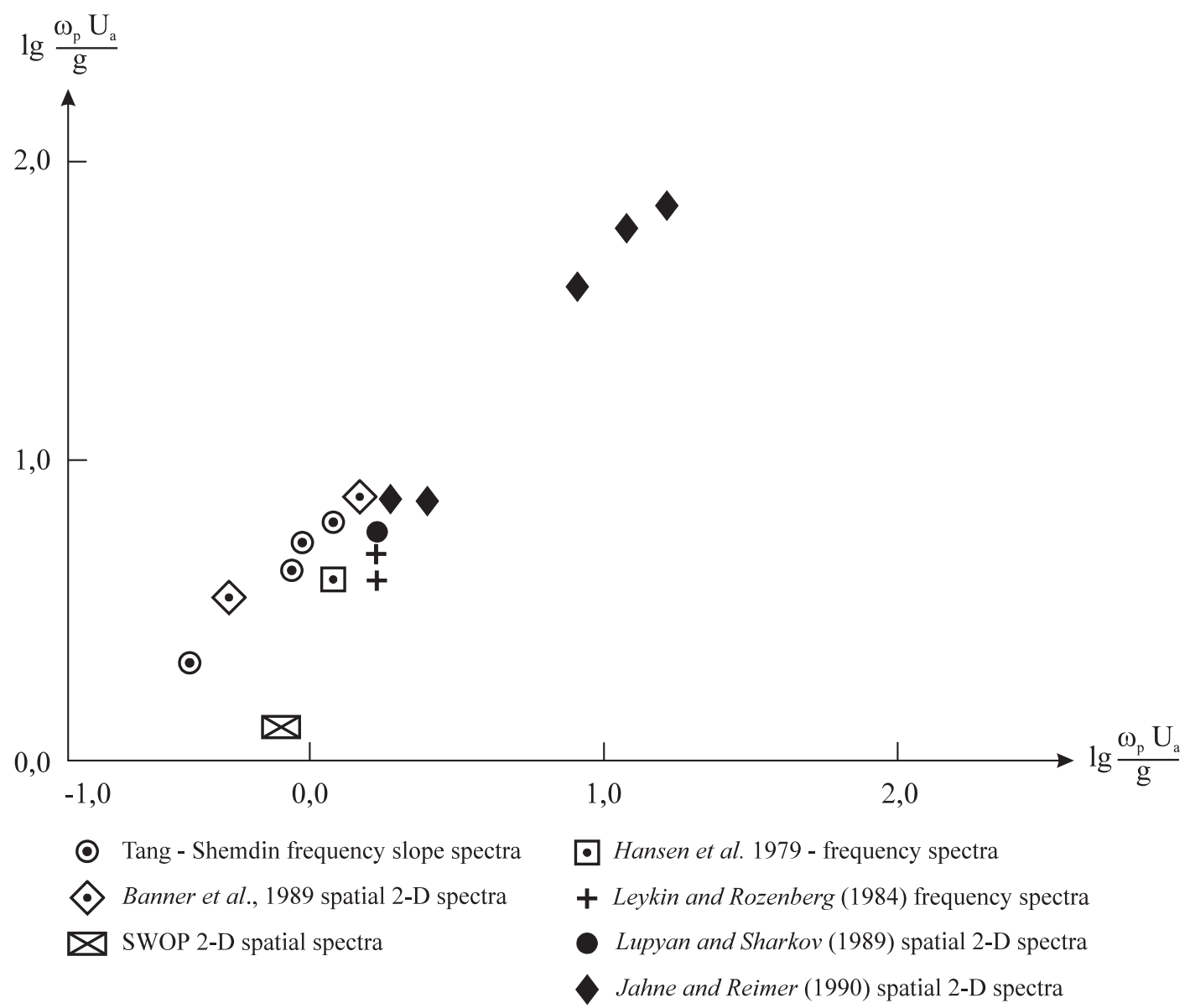


subrange (in our definition). To locate the transitional frequency $\frac{\omega_{g} U_{a}}{g}$ for Lupyan and Sharkov data, we use their Figure 3. As evident from this figure, the range of nondimensional fetches $\mathrm{gX} / \mathrm{U}_{\mathrm{a}}{ }^{2}$ is $6 \cdot 10^{3}-6 \cdot 10^{4}$, where $\omega_{\mathrm{p}} \mathrm{U}_{\mathrm{a}} / \mathrm{g}$ varies from 1,88 to 0,78 . Thus, the average value $\omega_{g} U_{a} / g=2,7$ can be placed at the average value $\omega_{p} U_{a} / g$ $=1.3$.

\section{Jahne and Riemer (1990) wave number spectra}

Jahne and Riemer (1990) presented very interesting laboratory data on twodimensional wavenumber spectra of small-scale water surface waves for fairly large fetch of $90 \mathrm{~m}$. The wave number spectra weighted by $\mathrm{k}^{4}$ were shown in their Figures 9 , 10 for different directions: a) along wind ( \pm 5$)$, b) $(30 \pm 5)$, c) $60 \pm 5$, together with unidirectional spectrum $\chi(\mathrm{k})$ integrated over all angles. The range of wind speeds was rather wide, from 2,7 to $17,2 \mathrm{~m} / \mathrm{s}$. The range of wavenumbers was $\mathrm{k} \approx 30-1000 \mathrm{~m}^{-1}$. The wave frequency spectra were measured with a slope gauge in the range $\mathrm{f}=0,1-100 \mathrm{~Hz}$. The inference from their data is that outside the gravity-capillary regime, i.e., at $\mathrm{k}<\mathrm{k}_{\mathrm{T}}$, only a slice through the wavenumbers along wind direction has a relatively clear transition from $\mathrm{k}^{-7 / 2}$ to $\mathrm{k}^{-4}$ for largest wind speeds. We choose three wind speeds, 17,2, 12,2 , and 8,8 , to determine the transitional wave number $\mathrm{k}_{\mathrm{g}}(\theta= \pm 5)$ from their spectra $\left(\mathrm{k}_{\mathrm{g}}=160 \mathrm{~m}^{-1}, 170 \mathrm{~m}^{-1}\right.$, and $180 \mathrm{~m}^{-1}$, respectively). This yields the following values: $\omega_{\mathrm{g}}$ $\mathrm{U}_{\mathrm{a}} / \mathrm{g}=69,58,37$. To locate these transitional frequencies, we use the JONSWAP dependence of $\omega_{p}$ on nondimensional fetches, which for the above cited wind speeds leads to $\mathrm{gX} / \mathrm{U}_{\mathrm{a}}{ }^{2}=3,0,6,0$, and 11,4 , respectively. For this rather small nonimensional fetches we choose the values $\omega_{p} U_{a} / g=17,2,11,9$, and 8,5, respectively (see Table 1). It is these three points that can still be considered outside the region influenced by surface tension. Thus, it is clear that very high values of $\omega_{\mathrm{g}}$ lie also in the region of very high values of $\omega_{\mathrm{p}} \mathrm{U}_{\mathrm{a}} / \mathrm{g}$ (even though the ratio $\omega_{\mathrm{g}} / \omega_{\mathrm{p}}$ varies slightly $4,0,4,8,4,45$ ). By using data of Jahne and Riemer (1990), it was possible to construct Figure 1, being more complete, than in Kitaigorodskii (1992a,b), which clearly demonstrates the dependence of the transitional frequency on fetch (or $\omega_{\mathrm{p}} \mathrm{U}_{\mathrm{a}} / \mathrm{g}$ ) (see Table 1 and Figure $1)$.

\subsection{Temporal characteristics of the wind-wave field}

\section{Tang and Shemdin (1983) frequency spectra of slope}

In Phillips (1985) paper on equilibrium spectra, experimental data used to prove the existence of wind-dependent statistical equilibrium field has been measurements by Tang and Shemdin (1983) of the frequency spectra of slope at a fixed point. Their results clearly indicate that the lower-frequency part of frequency spectra of slope $\mathrm{S}_{11}$ $(\omega)$ in the upwind and downwind directions, is independent on $\omega$. However, it is exactly 
the data in this Figure that we'll try now, as before, to interpret as noncontroversial evidence of the transition to the dissipation subrange in equilibrium spectra. The latter for slope, according to (33-35), must be independent of $\omega$ at frequencies $\omega$ between 2 rad. $\mathrm{s}^{-1}$ and $\sim 6$ rad. $\mathrm{s}^{-1}$ :

$$
S_{\zeta \zeta}(\omega)=S_{11}(\omega)+S_{22}(\omega)=A u * g^{-1}
$$

At higher frequencies, where Doppler shift effects can be significant and interpretation is difficult, the measured spectra obviously do not follow the form (39), but decrease approximately as $\omega^{-1}$ (see Figure 4 in Phillips (1985)), which can be interpreted as another asymptotic regime (36) corresponding to the dissipation subrange. At highfrequency range there is a good deal of sampling errors, without distinct trend in the spectral levels below about $7 \mathrm{rad} . \mathrm{s}^{-1}$. The spectral densities measured in the range (39) are generally consistent with the value of the Kitaigorodskii constant A, found in Kitaigorodskii (1983). Moreover Tang and Shemdin (1983) found that the downwind and transverse mean square slopes were nearly equal (isotropy) in cases of a wind field with a single well- defined peak. (but the most interesting feature of their Figure 4, the possible existence of the transition to the dissipation subrange, was not even mentioned in Phillips (1985), and that is why this analysis is presented here). Phillips (1985) argued that kinematic effects due to tidal currents and orbital peak velocities become serious at about $15 \mathrm{rad} / \mathrm{s}$, as well as dynamic limitations (capillary and influence of drift currents), whereas the transition from the frequency-independent flat part of slope spectra occurs in all spectra in Figure 4 at frequencies well below $15 \mathrm{rad} / \mathrm{s}$. Here are the main characteristics of the transition to the dissipation subrange derived by us from curves in Figure 4 in Phillips (1985).

Curve $1-\mathrm{u} * \approx 11 \mathrm{~cm} / \mathrm{s}$ and corresponding wind speeds are in the range 2,2-2,3 $\mathrm{m} / \mathrm{s}$, with value of $\omega_{\mathrm{g}}=15 \mathrm{rad} / \mathrm{s}($ ?) locates the transition to the dissipation subrange at $\omega_{\mathrm{g}} \mathrm{U}_{\mathrm{a}} / \mathrm{g} \approx 3,36-5,05$, which is close to $\omega_{\mathrm{g}} \approx 4 \mathrm{~g} / \mathrm{U}_{\mathrm{a}}$ - the best estimate of $\omega_{\mathrm{g}}$ according to Kitaigorodskii (1987), and Hansen et al. (1990). However, we'll discuss the value $\omega_{\mathrm{g}}$ $=15 \mathrm{rad} / \mathrm{s}$ in curve 1 in more detail below.

Curve $2-\mathrm{u}_{*} \approx 27 \mathrm{~cm} / \mathrm{s}$ and corresponding wind speeds $(8,1-7,1 \mathrm{~m} / \mathrm{s})$ with observed value of $\omega_{\mathrm{g}}=5,8-7,0 \mathrm{rad} / \mathrm{s}$ locates the transition to the dissipation subrange at $\omega_{\mathrm{g}} \mathrm{U}_{\mathrm{a}} / \mathrm{g} \approx 4,2-4,8$, again consistent with all previous estimates.

Curve $3-\mathrm{u} * \approx 28 \mathrm{~cm} / \mathrm{s}$ and corresponding wind speeds of 8,15-7,10 m/s with the observed value of $\omega_{\mathrm{g}}=7,0 \mathrm{rad} / \mathrm{s}^{-1}$ locates the transition to the dissipation subrange at $\omega_{\mathrm{g}}$ $\mathrm{U}_{\mathrm{a}} / \mathrm{g} \approx 5,0-5,82$, little bit higher value than the usually accepted 4,6 .

Curve $4-\mathrm{u}_{*} \approx 45 \mathrm{~cm} / \mathrm{s}$ and the corresponding wind speed in the range 11,8-14,5 with the observed value of $\omega_{\mathrm{g}}=5,0-5,5 \mathrm{rad} / \mathrm{s}$ locates the transition to the dissipation subrange at $\omega_{\mathrm{g}} \mathrm{U}_{\mathrm{a}} / \mathrm{g} \approx 6,0-8,1$, which is now much higher than the results from curve 1 and 2. To explain this trend in the movement of $\omega_{\mathrm{g}} \mathrm{U}_{\mathrm{a}} / \mathrm{g}$ (from curve 1) toward high frequencies (to curve 4), we have examined the original data by Tang and Shemdin (1983). 
First of all we have found that for curve 1 the choice of $\omega_{\mathrm{g}}=15 \mathrm{rad} / \mathrm{s}$ is illjustified. The choice closer to reality will be $\omega_{\mathrm{g}}=6 \mathrm{rad} / \mathrm{s}$, which leads to $\omega_{\mathrm{g}} \mathrm{U}_{\mathrm{a}} / \mathrm{g} \approx$ 2,14 . The latter value make the trend in $\omega_{\mathrm{g}} \mathrm{U}_{\mathrm{a}} / \mathrm{g}$ (from curve (1) to curve (4)) even more obvious. Table 1 presents the summary of Tang and Shemdin (1983), Banner et al. (1989), and SWOP results, together with results summarized in Table 1 of Hansen et al. (1990). The decrease of $\omega_{\mathrm{g}}$ with the movement of the peak frequency region toward low frequencies is evident. This is a very interesting and important support of the ideas of Kitaigorodskii (1983) about the existence of the dissipation subrange in wind wave spectra.

Very recently Jackson et al. (1992) in the extensive study of mean square slope data (mss) (based both on the microwave and the optical slicks) have found "that in order not to violate the constraints on the spectrum imposed by mss data, the $\mathrm{k}^{-7 / 2}$ wind speed dependent form of the nondimensional spectrum observed in the rear face region of the spectrum must transit to something more like the Phillips saturation $\mathrm{k}^{-4}$ form at wave numbers about 10 times the peak wavenumber". Their conclusion was that the mss data provided rather strong evidence in support of Kitaigorodskii's (1983) view. Since according to the above authors $\mathrm{k}_{\mathrm{g}} / \mathrm{k}_{\mathrm{p}} \approx 10$, this means that $\omega_{\mathrm{g}} / \omega_{\mathrm{p}} \approx 3,16$, the value which is not inconsistent with other data presented in Table 1 , The mean sea surface slope data, both the microwave and the optical slick and clean surface data, strongly support the idea that the $\mathrm{k}^{-7 / 2}$ equilibrium form cannot be extended to wavenumbers $\mathrm{k} \approx \mathrm{g} / \mathrm{u} *^{2}$, as was suggested in Phillips (1985). They are consistent much better with the model of the spectra including the dissipation subrange at $10<\mathrm{k} / \mathrm{k}_{\mathrm{p}}<$

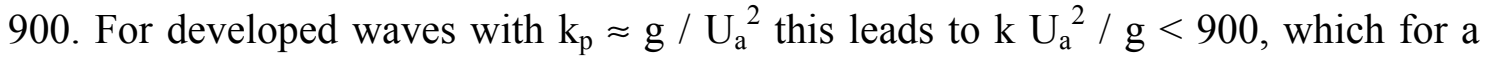
wind speed of $10 \mathrm{~m} / \mathrm{s}$ is still in the range of wavelengths $\lambda>7 \mathrm{~cm}$, i.e., still outside the region where surface tension $\left(\lambda_{\sigma}=3 \mathrm{~cm}\right)$ or viscosity $\left(\lambda_{v} \sim 0,3 \mathrm{~cm}\right)$ are important.

A usual approach used to estimate some transitional regime is actually limited by getting a certain typical average value of $\omega_{g} U_{a} / g$. The latter is also true for the data analysis in Leykin and Rozenberg (1984) to be discussed below.

\section{The frequency spectra without the dissipation subrange}

We also analyzed the data of Birch and Ewing (1986). In most cases their "transitional" frequency $\omega_{\mathrm{g}} \mathrm{U}_{\mathrm{a}} / \mathrm{g}$ was less than $\omega_{\mathrm{p}} \mathrm{U}_{\mathrm{a}} / \mathrm{g}($ (), which makes their study unsuitable for defining the dissipation subrange. By the way, the old Burling (1959) data, analyzed by Phillips (1958) and Kitaigorodskii (1962), have a range of $\omega_{\mathrm{g}} \mathrm{U}_{\mathrm{a}} / \mathrm{g} \approx$ $0,157-0,23$, also very close to $\omega_{\mathrm{p}}$ in their case, which makes them unsuitable for determination of the boundary of the dissipation subrange (Kitaigorodskii, 1997). Even data presented by Kahma and Calkoen (1993), which for the "grand" average of nondimensional spectra give clear vision of dimensionless frequency $\omega_{\mathrm{g}} \mathrm{U}_{\mathrm{a}} / \mathrm{g}$ about 5 as a possible transition to $\omega^{-5}$ region, we have found not adequate for searching on dissipation subrange existence, because for four (out of 7) group of the spectra in Lake 
Ontario where "transition" was observed $(7,6,5,3)$ the corresponding ratios of $\omega_{\mathrm{g}} / \omega_{\mathrm{p}}$ were equal to $1.15,1.25,1.14$, and 1.2, i.e., all of them were in the peak enhancement region.

\section{Leykin and Rozenberg (1989) spectra}

In Leykin and Rozenberg (1984) 20 spectra were chosen to characterize welldeveloped waves in the range of wind speeds of 3,5-13,5 m/s. The measured spectra within the frequency range from 2,4 to $7,2 \mathrm{~Hz}$ were analyzed in order to find an empirical description of the rear faces of the spectra. It was found that for all the spectra in the range, $1,2 \leq \omega / \omega_{p} \leq 3,2$, i.e., outside the peak enhancement region, there was a transition from the wind-dependent $\omega^{-4}$ form to the $\omega^{-5}$ form of saturation. To interpret this transition as a transition to the dissipation subrange, the Leykin and Rozenberg values of $\omega / \omega_{p}$ were recalculated into $\omega U_{a} / g$ assuming again $k_{p}=(2-4) g / U_{a}{ }^{2}$. This leads to $\omega_{\mathrm{p}}=(1,4-2) \mathrm{g} / \mathrm{U}_{\mathrm{a}}$, and with $\omega_{\mathrm{g}} \cong 3,2 \omega_{\mathrm{p}}$ (Figure 9 in Leykin and Rozenberg (1984)) to $\omega_{\mathrm{g}} \mathrm{U}_{\mathrm{a}} / \mathrm{g} \approx 4,48 \sim 6,4$ with an average value of $\omega_{\mathrm{g}} \mathrm{U}_{\mathrm{a}} / \mathrm{g} \approx 5,4$, which resembles the results of determination of the transition to the dissipation subrange reported by Hansen et al. (1990). In this frequency range Doppler shifts by peak orbital velocities as well as permanent drift currents are not important, so the Leykin and Rozenberg (1984) results can also be considered as an indirect proof of existence of the transition from the nondissipative form of the $\mathrm{k}^{-7 / 2}$ equilibrium spectra $\left(\mathrm{k} / \mathrm{k}_{\mathrm{p}} \leq 10\right)$ to the dissipation subrange $\left(\mathrm{k} / \mathrm{k}_{\mathrm{p}} \geq 10\right)$ with a broad angular distribution. Thus, the Leykin and Rozenberg frequency spectra (1984) can be interpreted basically in a similar way as in Hansen et al. (1990), i.e., in agreement with asymptotic prediction (33-36) of the theory of nondissipative and dissipative parts of equilibrium spectra.

\section{Empirical approach by M. Banner (1990)}

In a recent paper by Banner (1990) the emphasis was on the most detailed empirical description of fetch limited wave growth spectra given by Donelan et al. (1985, henceforth referred to as DHH). In the latter work the face of frequency spectra was successfully described by the $\omega^{-4}$ wind-dependent (linearly) form, excluding the peak enhancement region, but also in the region where Doppler shift effects by currents and orbital peak velocities were still unimportant. However, the DHH data, which covered almost all stages of wave growth, do not show a transition to the dissipation subrange, which, according to all previously analyzed data, must occur at smaller than $\omega / \omega_{\mathrm{p}} \approx 3$ scales. This transition was not even considered by Banner (1990), and he did not interpret $\omega^{-4}$ region as an equilibrium of the type (33-35). Instead of this, Banner (1990) choose a pure empirical canonical form of the spectra $\psi(\mathrm{k})$, corresponding to DHH data with an angular spreading distribution for $\mathrm{k} / \mathrm{k}_{\mathrm{p}} \leq 2,6$ (spreading cutoff does not occur at $\mathrm{k} / \mathrm{k}_{\mathrm{p}} \sim 2,6\left(\omega / \omega_{\mathrm{p}} \sim 1,6\right)$, extrapolated to much shorter scales consistent with the broad directional distribution observed by Banner et al. (1989). However, 
according to the latest Donelan's views (cited in Banner et al., 1989; see also Figures (3a-3b) in Banner (1990)) there is a transition to the most rapid spectral cutoff in Donelan data (personal communication), very similar to the one observed by LonguetHiggins et al. (1963) as a deviation from the $\omega^{-4}$ form for frequencies $\omega / 2 \pi>1 \mathrm{HZ}$. In Banner (1990), this fact was interpreted not as a transition to the dissipation subrange (Kitaigorodskii, 1983, 1987), but rather as a direct consequence of the DHH spectral form extrapolated to high wavenumbers with spreading cutoff occurring not before $\mathrm{k} /$ $\mathrm{k}_{\mathrm{p}} \geq 10$. However, DHH spectra in the range of $1,5<\omega / \omega_{\mathrm{p}}<3$ can be consistent with equilibrium form (33-35), with the energy flux $\varepsilon_{0}$ dependent on wave age $U_{a} / C_{p}$ in the following way

$$
\varepsilon_{0}=\left(\mathrm{C}_{\mathrm{p}} / \mathrm{U}_{\mathrm{a}}\right)^{3 / 2} \mathrm{U}_{\mathrm{a}}^{3} ; \alpha_{\mathrm{u}}=\left[\mathrm{S}(\omega) / \mathrm{g} \omega^{-4}\right] / \mathrm{U}_{\mathrm{a}} \cong 0,006
$$

where in Kitaigorodskii $(1983,1986)$ notations

$$
\varepsilon_{0}=\left(\mathrm{m} \rho_{\mathrm{a}} / \rho_{\mathrm{w}}\right) \mathrm{U}_{\mathrm{a}}^{3} ; \mathrm{m}=\left[0,006 /(2 \mathrm{~A})^{3}\right]\left(\mathrm{C}_{\mathrm{p}} / \mathrm{U}_{\mathrm{a}}\right)^{3 / 2}
$$

with the Kitaigorodskii constant A being of the order of unity (Kitaigorodskii, 1983) (A $=0,55-0,22)$. The fact that the energy flux $\varepsilon_{0}$ increases with wave growth $\left(C_{p} / U_{a}\right)$ is in agreement with results of direct calculations of nonlinear interaction in wave generation models. Thus, we can argue that DHH results, together with Banner's (1990) additional information, are not inconsistent with our hypothesis for the existence of equilibrium form (33-35) with the transition to the dissipation subrange, as it was observed in Hansen et al. (1990). According to the latter work, the average value of $\alpha_{u}$ in equilibrium spectra $(33-35,41)$ is equal to $4,4 \cdot 10^{-3}$, which together with the observed transition to the dissipation subrange at $\alpha_{\mathrm{u}} \cdot 10^{3}\left(\omega_{\mathrm{g}} \mathrm{U}_{\mathrm{a}} / \mathrm{g}\right) \approx 2,7$ leads to the average value of transitional frequency $\omega_{\mathrm{g}} \approx 6,1 \mathrm{~g} / \mathrm{U}_{\mathrm{a}}$. This is higher than $\omega_{\mathrm{g}} \approx 4 \mathrm{~g} / \mathrm{U}_{\mathrm{a}}$, probably due to the Doppler shift effects, but still with observed range of $\omega_{\mathrm{p}} \mathrm{U}_{\mathrm{a}} / \mathrm{g} \approx 1$ 3 roughly corresponds to $\omega_{\mathrm{g}} / \omega_{\mathrm{p}} \geq 3$, which is in good agreement with Donelan et al. (1985).

As a summary of this paragraph, we can make a statement that besides the results of Kitaigorodskii publication in 1983, 1986, the data which were analyzed here at least do not contradict the hypothesis that there is a transition from equilibrium form (33-35) to the dissipation subrange (36). The variability of the lower frequency boundary of the dissipation subrange discussed above is shown in Figure 1, together with the data published by Hansen et al. (1990). 
4. Generalizations of asymptotic laws for nondissipative and dissipative parts of equilibrium spectra (fractal description of the sea surface)

4.1 The power approximation of wind-wave spectra throughout the entire equilibrium range

When deriving expression (36) corresponding to the Phillips (1958) saturation form, we considered an asymptotic situations corresponding to indefinitely large values of $\mathrm{k} / \mathrm{k}_{\mathrm{g}}$ (indefinitely large values $\mathrm{k}$ or $\varepsilon_{0}$ ), where the statistical characteristics of the wave field were determined solely by the process of wave breaking. Therefore, the magnitude of the spectrum in the dissipation subrange (36) represents, according to Phillips (1958), the upper limit of $\mathrm{F}_{\mathrm{k}}$, dictated by the requirement of crest attachment. Generally speaking, we cannot in principle disregard the possibility (because of the very nature of asymptotic arguments) that for $\left(\varepsilon_{0} \rightarrow \infty\left(\lambda_{\mathrm{g}} \rightarrow \infty, \mathrm{k} \lambda_{\mathrm{g}} \rightarrow \infty\right)\right.$ the values of $\mathrm{F}_{\mathrm{k}}$ and $\mathrm{N}_{\mathrm{k}}$ (hence $\mathrm{S}(\omega)$ ) continue to depend no matter how slightly on $\varepsilon_{0}$, so that instead of (33-35) we have

$$
\begin{aligned}
& \mathrm{N}_{\mathrm{k}}=\mathrm{A} \varepsilon_{0}{ }^{1 / 3} \mathrm{k}^{-4}\left(\mathrm{k} / \mathrm{k}_{\mathrm{g}}\right)^{-\mathrm{p}} \\
& \mathrm{F}_{\mathrm{k}}=\mathrm{A} \varepsilon_{0}{ }^{1 / 3} \mathrm{~g}^{-1 / 2} \mathrm{k}^{-7 / 2}\left(\mathrm{k} / \mathrm{k}_{\mathrm{g}}\right)^{-\mathrm{p}} \\
& \mathrm{S}(\omega)=2 \mathrm{~A} \varepsilon_{0}{ }^{1 / 3} \mathrm{~g} \omega^{-4}\left(\omega / \omega_{\mathrm{g}}\right)^{-2 \mathrm{p}}
\end{aligned}
$$

where $\omega_{\mathrm{g}}$ and $\mathrm{k}_{\mathrm{g}}$ are given by expressions $(32,37)$, and $\mathrm{p}$ is power exponent such that to satisfy the predictions $(35,36)$, it must be

$$
1 / 2 \geq p \geq 0
$$

By replacing $\varepsilon_{0}$ (according to (40)) and $\mathrm{k}_{\mathrm{g}}$ (according to (37)), (42-44) is reduced to the usual wind-dependent similarity form of the wind wave spectra (Kitaigorodskii (1962, 1986)). However, the value of $\mathrm{p}$ cannot be derived from dimensional considerations only, and the frequency spectra of the type of (44) was first analyzed by Barenblatt and Leykin (1981). They were looking for the variations of $p$ with the change in the stage of wave development (or in their terminology, with the nondimensional parameter $\lambda_{0}=$ $\mathrm{g} \lambda_{\mathrm{p}} / \mathrm{U}_{\mathrm{a}}^{2}$, where $\lambda_{\mathrm{p}}$ is a peak wave length. According to their analyses, the average value of $\mathrm{p}$ is close to $0(\mathrm{p}=0,4 \pm 0,4)$ in the range $\lambda_{0}=3-8$, which corresponds to the range of $\omega_{\mathrm{p}} \mathrm{U}_{\mathrm{a}} \cdot / \mathrm{g} \approx 1,25-2,05$. The latter is very close to conditions of well-developed waves, characterized by $\mathrm{k}_{\mathrm{p}}=2-4 \mathrm{~g} / \mathrm{U}_{\mathrm{a}}^{2}$. Thus, our interpretation of the data presented in Barenblatt and Leykin (1981) and Leykin and Rozenberg (1984) is that in the region of $1,3<\omega / \omega_{\mathrm{p}}<3$ (i.e., outside the peak enhancement region and Doppler shift effects) the frequency spectra are close to the equilibrium form (33-35) $p \approx 0$ with the possible 
transition to the dissipation subrange (36) only at $\omega_{\mathrm{g}} \geq 3 \omega_{\mathrm{p}}$ (Leykin and Rozenberg, 1984) or approximately at $\omega_{\mathrm{g}}=(3,75-6,0) \mathrm{g} / \mathrm{U}_{\mathrm{a}}$. This is again close enough to what was observed by the others, including DHH. The similar approach was used for 1-D and 2-D spatial spectra by Banner et al. (1989), whose data we have analyzed before. Banner et al. (1989) used expression for 1-D spectra of the form

$$
\phi\left(\mathrm{k}_{\mathrm{i}}\right) \sim\left(\mathrm{U}_{*}^{2} \mathrm{k}_{\mathrm{i}} / \mathrm{g}\right)^{\gamma} 2 \mathrm{k}_{\mathrm{i}}^{-3},(\mathrm{i}=1,2),\left(\mathrm{k}=\mathrm{k}_{1}, \mathrm{k}_{2}\right)
$$

where $\gamma=(1 / 2-p)$ was also found to be close to 0 (actually $\gamma=0,09 \pm 0,09$ at the $95 \%$ confidence level). Thus, Banner et al. (1989) confirm the asymptotic predictions corresponding to $p=1 / 2$, embracing the wind-dependent approximation to the observed one-dimensional and two-dimensional wave number spectra, with some evidence of existence of the transition to the dissipation subrange (see sections 3 ).

The most important results of our data analysis are presented in Table 1 and Figure 1, which summarize determinations of the transitions to the dissipation subrange according to the different authors. The future more comprehensive studies of wave characteristics hopefully will permit to check the results presented in Table 1 and Figure 1.

Table 1. Nondimensional transitional frequencies $\omega_{g} U_{a} / g$ for different stages of wave development $\left(U_{a} \omega_{p}\right.$ $/ \mathrm{g})$.

\begin{tabular}{ccccl}
\hline$\omega_{\mathrm{g}} \mathrm{U}_{\mathrm{a}} / \mathrm{g}$ & $\omega_{\mathrm{p}} \mathrm{U}_{\mathrm{a}} / \mathrm{g}$ & $\lg \omega_{\mathrm{g}} \mathrm{U}_{\mathrm{a}} / \mathrm{g}$ & $\lg \omega_{\mathrm{p}} \mathrm{U}_{\mathrm{a}} / \mathrm{g}$ & Source \\
\hline 6,0 & 1,20 & 0,78 & 0,08 & Tang-Shemdin frequency \\
5,35 & 0,96 & 0,728 & $-0,017$ & slope spectra \\
4,5 & 0,89 & 0,65 & $-0,05$ & \\
2,14 & 0,39 & 0,33 & $-0,40$ & \\
\hline 3,5 & 0,54 & 0,54 & $-0,26$ & Banner et al., 1989 spatial \\
7,5 & 1,54 & 0,87 & 0,18 & 2-D spectra \\
\hline 1,28 & 0,78 & 0,10 & $-0,107$ & SWOP 2-D spatial spectra \\
\hline 7,36 & 2,58 & 0,86 & 0,41 & Hansen et al., 1992 \\
7,45 & 1,91 & 0,87 & 0,28 & frequency spectra \\
5,73 & 1,74 & 0,75 & 0,24 & \\
4,05 & 1,23 & 0,60 & 0,09 & \\
\hline 5,4 & 1,65 & 0,73 & 0,217 & Leykin and Rozenberg \\
4,87 & 1,65 & 0,68 & 0,217 & frequency spectra 1984 \\
\hline 2,7 & 1,3 & 0,43 & 0,11 & Lupyan and Sharkov \\
& & & & spatial 2-D spectra 1989 \\
\hline 69 & 17,2 & 1,84 & 1,23 & Jahne and Riemer, 1990 \\
58 & 11,9 & 1,76 & 1,07 & spatial 2-D spectra \\
37,7 & 8,47 & 1,57 & 0,92 & \\
\hline
\end{tabular}


4.2. The relationship between intrinsic microscale in fractal description of sea surface and transitional wave number $k_{g}$

The power approximations $(42-44,46)$ were very often used in conjunction with consideration of the equilibrium range exponent as a monotonic function of the degree of sea development. This assumption was used in both Barenblatt and Leykin (1981) and Glazman (1990). In latter it was emphasized that with power-law approximations the rapid spectral cut off (in our definition at $\lambda_{\mathrm{g}}=2 \pi / \mathrm{k}_{\mathrm{g}}$ ) is an intrinsic property of a well-developed sea. The existence of this cut off is supported by the fact that the downward acceleration of particles can reach (or exceed) g when «breaking» takes place, or by the fact that the actual steepness $\gamma_{\omega}$ of individual wavelets is limited due to hydrodynamic instability of steep gravity waves, which tend to break when $\gamma_{\omega}$ approaches a certain value. It was shown in Classman (1988) that in the range of wavenumbers

$$
\mathrm{k} / \mathrm{k}_{\mathrm{p}}<\mathrm{k} / \mathrm{k}_{\mathrm{g}}<1
$$

the statistical characteristics of a random wave field (42-44) represent a «fractal regime»' typical of the equilibrium range cascade as in Kolmogoroff's turbulence.

This means that the field variations at distances exceeding the average value of the scale $\lambda_{\mathrm{g}}$ are very erratic and represent a surface with a discontinuous r.m.s. slope. In other words, the surface on these scales appears as a fractal one. Contrary to this, the case

$$
\mathrm{k} / \mathrm{k}_{\mathrm{g}}>1
$$

can be referred to as a regular regime because the field variations within short distances are smooth (short-range asymptotics of the structural function $D(r) \sim r^{2}$ corresponds to a regular surface), and thus the dissipation subrange in wind-wave spectra (previously associated with a saturation form of the spectra) corresponds to a regular regime, where the superposition principle is a good approximation. This means that sharp crests are associated with the range of intermediate but not high enough wavenumbers of the surface gravity wave field where tractalization can be due to surface tension effects. As shown by Classman (1988) and some others, the Hausdorff dimension of a Gaussian surface corresponding to (42-45) is given by $D_{H}=(5-2 p) / 2$ and, hence, lies inside the limits 2,5-2,0. Therefore, $\mu=(1 / 2-p) / 2$ represents a co-dimension of the surface. A particular consequence of $\mathrm{p}<1 / 2$ is that between two basic wave crests separated by the mean dominant wavelength $\lambda_{p}=2 \pi / k_{p}$, there emerge a large number of secondary wave crests, which appear due to a cascade pattern in surface geometry (Glazman, 1986, 1988; Glazman and Weichman, 1988). For the dissipation subrange form of the spectra Glazman (1990) suggested the exponentially decreasing function k / $\mathrm{k}_{\mathrm{g}}$, i.e., at k $/ \mathrm{k}_{\mathrm{g}}>1, \mathrm{~F}(\mathrm{k})=\psi_{\mathrm{eq}}(\mathrm{k}) \exp \left\{-\left(\mathrm{k} / \mathrm{k}_{\mathrm{g}}\right)^{2}\right\}$, where $\psi_{\mathrm{eq}}(\mathrm{k})$ can be a form of equilibrium 
spectra $\mathrm{k}^{-7 / 2}$. According to Glazman (1990) estimates, at least for the known observations for short fetch cases the surface intrinsic smoothing microscale $1 / \mathrm{k}_{\mathrm{g}} \approx 0,4$ $\mathrm{m}$. If $1 / \mathrm{k}_{\mathrm{g}}=\mathrm{g} / \omega_{\mathrm{g}}{ }^{2} \approx 0,4 \mathrm{~m}$ and if on average a typical value of $\omega_{\mathrm{g}}$ is $\omega_{\mathrm{g}} \approx 4 \mathrm{~g} / \mathrm{U}_{\mathrm{a}}$, this gives $\underline{U}_{a} \cong 6 \mathrm{~m} / \mathrm{s}$, a very reasonable value of wind speed. Zakharoff (1992) derived the same value of wind speed on the basis of the condition that fractalization of the sea surface takes place only if $\lambda_{\mathrm{g}} \geq \lambda_{\mathrm{T}}\left(\lambda_{\mathrm{T}}=2 \pi / \mathrm{k}_{\mathrm{T}}\right)$, where $\lambda_{\mathrm{T}} \approx\left(\left(\mathrm{T} / \rho_{\mathrm{a}}\right) / \mathrm{g}\right)^{1 / 4}$ is a surface tension wavenumber, and $\lambda_{\mathrm{g}}=\varepsilon\left(\mathrm{U}_{\mathrm{a}}^{2} / \mathrm{g}\right)\left(\varepsilon=\rho_{\mathrm{a}} / \rho_{\omega}\right)$. Then the condition $\lambda_{\mathrm{g}} \approx \lambda_{\mathrm{T}}$ also leads to $U_{\mathrm{a}}=6 \mathrm{~m} / \mathrm{s}$. However, we have used empirically derived values of $\mathrm{k}_{\mathrm{g}}$ based on spectral analyses, and it is a priori clear that these values of $\mathrm{k}_{\mathrm{g}}$ are most likely to coincide with $\mathrm{k}_{\mathrm{g}} \approx \varepsilon^{1 / 2}\left(\mathrm{~g} / \mathrm{U}_{\mathrm{a}}{ }^{2}\right)$. In this case $\mathrm{U}_{\mathrm{a}}=(\varepsilon)^{-1 / 4}((\mathrm{~T} / \rho) \mathrm{g})^{1 / 4}$, which leads to $\mathrm{U}_{\mathrm{a}}=$ $1,17 \mathrm{~m} / \mathrm{s}$, a too low value compared with $U_{a}=(\varepsilon)^{-1 / 2}(T / \rho g)^{1 / 4}=6,4 \mathrm{~m} / \mathrm{s}$. Therefore, the limitation of fractalization of the sea surface due to surface tension is very unlikely for such small values of wind speed as $1,17 \mathrm{~m} / \mathrm{s}$, and the direct cascade of energy on such scales has probably never existed.

\section{Conclusions}

We can conclude that available data on the frequency and spatial characteristics of the wind-wave field are not inconsistent with our assumption (Kitaigorodskii, 1983) of the existence of the transition to the dissipation subrange at high wave numbers and frequencies. Moreover, it appears that in most cases such transition is also definitely associated with the existence of equilibrium energy cascade pattern in wind wave spectra on scales larger than the transitional scale $\lambda_{\mathrm{g}}=2 \pi / \mathrm{k}_{\mathrm{g}}$. When completing this paper the financial support by the Academy of Finland to the author is gratefully acknowledged.

\section{References}

Banner, M.L., I.S.F. Jones and J.C. Trinder, 1989. Wavenumber spectra of short gravity waves. J. Fluid Mech., v. 198, pp. 321-344.

Banner, M.L., 1990. Equilibrium spectra of wind waves. J. Phys. Oceanography, v. 20, p. $966-984$.

Barenblatt, G.I. and I.A. Leykin, 1981. On the self-similar spectra of wind waves in the high frequency range. Izv. Atmos. Oceanic Phys. vol. 17, no. 1, pp. 50-58.

Birch, K.G. and J.A. Ewing, 1986. Observations of wind waves on a reservoir. Institute of Oceanographic Sciences, Report No 234,. England

Cote, L.T., T.O. Davis, W. Marks, R.T. McGough, E. Nehr, W.T. Pierson, Jr., T.F. Ropek, G. Stephenson and R.C. Vetter, 1960. The directional spectrum of windgenerated sea as determined from data obtained by the Stereo wave observation Project. Meteor. Pap. New York University, College of Engineering, Vol. 2, no. 6, $88 \mathrm{pp}$. 
Donelan, V.A., J. Hamilton and W.M. Hui, 1984. Directional spectra of wind-generated waves. Phil. Trans. Roy. Soc. London, A315, pp. 509-562.

Glazman, R.E., 1988. Fractal nature of surface geometry in a developed sea, In: Scaling, Fractals and Nonlinear Variability in Geophysics, Eds. S. Lovejoy and D. Schertser, D. Reidel Publishing Co.

Glazman, R.E., 1990. Near-nadir radar backscatter from a well developed sea. Radio Science, 25(6), 1211-1219.

Glazman, R.E. and P. Weichman, 1989. Statistical geometry of small surface patch in a developed sea. J. Geophys. Res., 94(4), 4998-5010.

Hansen, C., K.B. Katsaros, S.A. Kitaigorodskii and S.E. Larsen, 1990. The dissipation range of wind-wave spectra observed on a lake. J. Phys. Oceanography, v. 20. p. 1264-1277.

Jackson, P.C., W.T. Walton, B.A. Walter, and Peng, C.Y., 1992. Sea surface mean square slope from Ku-band backscatter data. Journal of Geophysical Research, Vol. 97, No C7, 11.411-11.427

Jahne, B., and K.S. Riemer, 1990. Two dimensional wavenumber spectra of small scale water surface waves. J. Geophysical Res., 95, C. 7, pp. 11531-11546.

Kahma, K.K. and Ch.J. Calkoen, 1992. Reconciling discrepancies in the observed growth of wind-generated waves. Journal of Physical Oceanography, v. 22, n. 12, pp. 1389-1405.

Kitaigorodskii, S.A., 1962. Applications of the similarity theory to the analysis of wind wave as random processes. Izvestiya AN USSR, Ser. Geofiz, nI, pp. 105-117.

Kitaigorodskii, S.A., 1983. On the theory of the equilibrium range in the spectrum of wind-generated gravity waves. J. Phys. Oceanography, v. 13, n. 5, pp. 817-827.

Kitaigorodskii, S.A., 1986. The equilibrium range in wind-wave spectra (Physical arguments and experimental evidence for and against their existence). Wave Dynamics and Radio Probing of the Ocean Surface, ed., O.K. Phillips and K. Hasselmann Plenum Publishing Corporation.

Kitaigorodskii, S.A., 1987. A general explanation of the quasi-universal form of the spectra of wind generated gravity waves at different stages of their development. Johns Hopkins APL Technical Digest, v. 8, n. 1, pp. 11-14.

Kitaigorodskii, S.A., 1992a. The dissipation subrange in wind-wave spectra (experimental evidence). Det Kongelige, Videnskabernes selskab, MatematiksFysiske meddelelseer, 42-5. Copenhagen.

Kitaigorodskii, S.A., 1992b. The dissipation subrange of wind-wave spectra. Breaking waves IUTAM Symposium Sydney, Australia, 1991, B.M.L. Banner, R.H.S. Grimshau (eds), pp. 200-206. Spinger-Verlag, Berlin Heidebberg.

Kitaigorodskii, S.A., 1997. On the employment of the similarly theory methods for analyzing of wind wave spectra. Izvestya RAN, Physics of Ocean and Atmosphere, Vol 33, No 5, pp. 715-718. 
Kitaigorodskii, S.A., V.P. Krasitskii, and M.M. Zaslavskii, 1975. On Phillips' theory of equilibrium range in the spectra of wind-generated gravity waves. J. Phys. Oceanography, v. 5, p. 410-421.

Komen, G.T., S. Hasselmann, and K. Hasselmann, 1984. On the existence of a fully developed wind-sea spectrum. J. Phys. Oceanography, v. 14, pp. 1271-1285.

Leykin, I.A. and A.D. Rozenberg, 1984. Sea tower measurements of wind-wave spectra in the Caspian Sea. J. Phys . Oceanography, v. 14, pp. 168-176.

Longuet-Higgins, M.S., D.E. Cartwright and N.D. Smith, 1963. Observations of the directional spectra of sea waves using the motion of a floating buoy, In: Ocean Wave Spectra, pp. 111-136, Prentice Hall.

Lupyan, E.A. and E.A. Sharkov, 1989. Developed spectra of wind waves (manuscript).

McLeish, W. and D.B. Ross, 1983. Imaging radar observations of direction properties of ocean waves. J. Geophys. Res., v. 88, pp. 4407-4419.

Phillips, O.M., 1958. The equilibrium range in the spectrum of wind generated ocean waves. J. Fluid. Mech., v. 4, pp. 426-434.

Phillips. O.M., 1977. The dynamics of the upper ocean. 2 nd ed., Cambrudge University Press.

Phillips, O.M., 1985. Spectral and statistical properties of the equilibrium range in wind generated gravity waves. J. Fluid Mech., 156, p. 505-531.

Tang, S. and O.K. Shemdin, 1983. Measurements of high frequency waves using a wave follower. J. Geophys. Res., v. 88, pp. 9832-9840.

$\mathrm{Wu}$, J., 1990. Radar sea returns, ocean ripple spectrum and breaking wave inflience. $J$. Phys. Oceanography, v. 20, pp. 1985-1993.

Zakharoff, V.E. 1992 Inverse and direct cascade in the wind-driven surface wave turbulence and wave breaking. pp. 70-91., M.L.Banner, R.H.J. Grimshaw (eds). Breaking waves IUTAM simposium (Sydney, Australia) Springer-Verlag. BerlinHeidelberg.

Zakharoff, V.E. and N.N. Filonenko, 1966. The energy spectrum for random surface waves. Dokl. Akad. Sci. SSSR, 170, pp. 1291-1295.

Zakharoff, V.E. and M.M. Zaslavskii, 1982. The kinetic equation and Kolmogorov spectra in the weak-turbulence theory of wind waves, Izvestiya Atmos. Oceanic Phys., v. 18. p. 747-753.

Zakharoff, V.E. and M.M. Zaslavskii, 1983. Shape of the spectrum of energy-carrying components of a water surface in the weak-turbulence theory of wind waves, Izvestiya Atmos. Oceanic. Phys. (English translation), v. 19 (3), pp. 207-212.

Zaslavskii, M.M., 1998. On the blockage interval in the spectrum of wind generated gravity waves. Izvestiya Atmos. Oceanic Physic, in press. 